\title{
FROM NUCLEAR PHASE-OUT TO RENEWABLE ENERGIES IN THE SWISS ELECTRICITY MARKET
}

\author{
Sebastian Osorio \\ University of Lausanne, Faculty of Business and Economics (HEC Lausanne) \\ Quartier UNIL-Dorigny, Anthropole, 1015 Lausanne, Switzerland \\ sebastian.osorio@unil.ch
}

Ann van Ackere

University of Lausanne, Faculty of Business and Economics (HEC Lausanne)

Quartier UNIL-Dorigny, Anthropole, 1015 Lausanne, Switzerland

ann.vanAckere@unil.ch

\begin{abstract}
Liberalization and the ever larger share of variable renewable energies (VRES), e.g. photovoltaic (PV) and wind energy, affect security of supply (SoS). We develop a system dynamics model to analyse the impact of VRES on the investment decision process and to understand how SoS is affected. We focus on the Swiss electricity market, which is currently undergoing a liberalization process, and simultaneously faces the encouragement of VRES and a nuclear phase out. Our results show that nuclear production is replaced mainly by PV and imports; the country becomes a net importer. This evolution points to a problem of capacity adequacy. The resulting price rise, together with the subsidies needed to support VRES, lead to a rise in tariffs. In the presence of a high share of hydro, the de-rated margin may give a misleading picture of the capacity adequacy. We thus propose a new metric, the
\end{abstract}


annual energy margin, which considers the energy available from all sources, while acknowledging that hydro-storage can function as a battery. This measure shows a much less reassuring picture of the country's capacity adequacy.

Keywords: Swiss electricity market, system dynamics, renewable energies, security of supply, capacity adequacy. 


\section{INTRODUCTION}

Before the 1980s, electricity was mainly produced using hydro-power, nuclear and thermalbased units. Most markets were monopolies, whose only concern was to ensure capacity adequacy (Lieb-Dóczy et al., 2003). The liberalization process of electricity markets, which started in the 1990s, has led to the creation of competitive wholesale and retail markets and the unbundling of the sector segments (generation, transmission and distribution), often resulting in the privatisation of generators (Joskow, 2006). As a consequence, guaranteeing the electricity supply has become more complex. In this paper we focus on the challenges currently faced by Switzerland, one of the last European countries to start a liberalisation process.

Liberalisation enhances competition among generators, resulting in investment decisions being increasingly based on profitability, at the expenses of system security (Lieb-Dóczy et al., 2003). The resulting lack of coordination in investments results in price and capacity cycles, which add complexity to the investment decision process (Arango and Larsen, 2011).

The electricity sector has also experienced several changes in generation technologies. Combined cycle gas turbines (CCGT) gained in importance in the 1990s due to significant efficiency improvements, reduced pollution and shorter construction lead times (Ford, 1997). Over the last two decades, governments have encouraged investments in renewable generation, mostly in variable renewable energies (VRES), i.e., solar and wind. However, these technologies create a new challenge for the sector. Their availability factors are significantly lower than those of, e.g., thermal generation, and their production is subject to inherent variability that needs to be balanced in real-time (Lise et al., 2013). Additionally, their large penetration has a price-lowering effect, which decreases the profitability of other generators. However, consumers do not benefit from these lower prices as they are charged 
cost of the subsidising renewable energies (BMWi, 2014). The uncertainty concerning new investments and rising tariffs due to VRES subsidies affects numerous markets. Many countries are thus facing the challenge of providing increasing amounts of affordable 'green' electricity, in the right place, at the right time.

Additionally, electricity markets are increasingly interconnected. This can improve security of supply (SoS) as it gives countries access to more supply, and helps balancing the load, e.g., in countries with complementary seasonal patterns. However, a high degree of dependency can discourage new investments in the long-term, negatively impacting SoS (Ochoa and van Ackere, 2009).

Although assessing SoS has been mainly addressed as a capacity adequacy problem, today other aspects such as import dependency, environmental issues and tariff affordability must be considered. Actions to enhance capacity adequacy may conflict with economic efficiency or environmental protection or both. Thus, understanding the dynamics of electricity markets is a necessity to develop appropriate policies.

We develop a simulation model calibrated to the Swiss electricity market to analyse the investment decision process and the impact on SoS of the changing generation mix. The model is developed using system dynamics (SD), which aims mainly at understanding a problem based on its causal structure, by analysing the feed-back loops among the key variables (Sterman, 2000). This methodology provides several advantages including (i) visualizing the interactions and causal relationships between the different variables, (ii) providing understanding of the impact of delays on the system's evolution, and (iii) allowing evaluating SoS under different scenarios of energy policy. 
As shown in Table 1, in 2013 nuclear energy accounted for 36\% of Swiss electricity generation and hydro-power for 58\%, split between run-of-river (26\%) and hydro-storage (32\%). The share of other sources was only 6\%, with PV and wind energy accounted for barely $1 \%$ (SFOE, 2014a). However, the government is strongly encouraging these technologies through feed-in tariffs (FiTs). For instance, the FiT for PV installed since January $1^{\text {st }}, 2014$, lasts 20 years, and varies, depending on the nominal capacity, between 172 and $304 \mathrm{CHF} / \mathrm{MWh}^{1}$. It is noticeable that PV capacity has increased nearly ten-fold between 2009 and 2013: 755 MW compared to 79 MW (SFOE, 2014a). Switzerland appears selfsufficient, achieving net exports equivalent to $3 \%$ of net production. However, when considering the hydraulic year, we observe net exports of 2.0 TWh between September 2012 and August 2013, but net imports of 2.6 TWh between October 2012 and April 2013, indicating a strong import dependency in winter.

Switzerland currently benefits from long-term contracts for importing cheap off-peak energy from France but they will expire by 2040 (AES, 2012). Since the Federal Council plans to gradually decommission the nuclear power capacity, SoS is threatened in the middle- and long-term. The government expects VRES to partly replace the expiring contracts and the capacity that will be dismantled.

Besides the support to VRES, the government and the Swiss Federal Office of Energy (SFOE) aim to create a favourable framework for CCGT. This technology's availability is similar to nuclear power and it is flexible enough to complement hydro-storage to meet the balancing needs resulting from VRES. However, the high emissions challenge its profitability (carbon costs) and its acceptance by the Swiss population.

\footnotetext{
${ }^{1} 1 \mathrm{CHF}=0.92$ Euro (exchange rate December 2015).
} 
The next section motivates the methodology (SD) and describes the model. In Section 3 we present our results and we conclude with a discussion of policy implications.

\section{METHODS}

Gary and Larsen (2000) argue that traditional economic equilibrium models do not adequately address the issues faced by recently liberalized industries: during their transition to competitive markets they do not comply with the equilibrium assumptions. We therefore model the system's structure explicitly to gain understanding of the dynamics of the industry, using SD.

SD models take a system's view of strategic problems and focus on capturing the feedback mechanisms (created by a series of causal relationships) and time delays that define the structure of a system as understood by the decision makers (Sterman, 2000). The system is represented by a set of differential equations. Modelling causality and delays is important in energy policy formulation since this helps investigate whether policies trigger instabilities which may affect future system performance (Arango, 2007). SD has been used to explain the dynamics of electric markets. Bunn and Larsen (1992), Ford (1999) and Ochoa (2007) were among the first to use SD to analyse how these new investment dynamics impact capacity adequacy, and in turn the SoS, in respectively England and Wales, the western market of the U.S.A., and Switzerland. More recently Pereira and Saraiva (2013) developed an hybrid SDoptimisation model for the Spanish-Portuguese market to evaluate expansion plans in view of the increased renewable generation. A detailed review of the main system dynamics models used to simulate electricity systems can be found in Teufel et al. (2013).

SD is particularly suitable for capturing the dynamics of markets at an early stage of liberalisation since it allows incorporating bounded rationality and stakeholders' behaviour. 
Given that there is no historical data for a competitive Swiss market, this approach offers an attractive way of understanding how the market might evolve, generating for instance insights into the effect of price shocks or parameter uncertainties as well as illustrating potential undesirable consequences of the proposed regulation (Larsen and Bunn, 1999). Given the huge uncertainty concerning the future of nuclear power in Switzerland, the possibility to evaluate different scenarios is essential.

Our model includes VRES generation and expansion, which allows us to understand their long-term effect on the SoS. The model is divided into three modules: market clearance and electricity exchange, which are shown in Figure 1, and the investment decision process is presented in Figure 2. These diagrams show the relations among the main variables, whose interactions determine the dynamics of electricity markets.

Figure 1 explains how the market is cleared. Total demand results from the local demand and the net flow of electricity exchange. Loops B1 and B2 explain the balance of exchanges (imports and exports). If total demand grows, the gap between supply and total demand (Gap $S-D)$ will fall. Since the merit order dispatch depends on marginal costs, a tighter Gap $S$ - $D$ leads to higher prices. The market price is compared to the price abroad to determine whether the country imports (B1) or exports (B2).

Investment dynamics (Figure 2) represent Ford's (2002) theory of investor behaviour, according to which investment decisions are based on expected profitability. Such expectations are affected by expectations of future prices and costs, as well as competitors' investments. Capacity construction is thus encouraged by high profits, and in turn increases the future supply. As explained before, a higher expected supply leads to lower prices and, in turn, to lower profits. Hence, a balance is reached since lower profits discourage further investments (loops B3 and B4). The investors' expected profitability depends also on their 
expected costs $\left(\mathrm{LCOE}^{2}\right)$. According to Ueckerdt et al. (2013), using LCOE for comparing technologies, in particular VRES with non-VRES, is not appropriate because VRES create balancing, grid and profile costs for the system. However, these costs are not supported by investors, who decide based on their financial costs.

If VRES are supported by FiTs, they always receive a fixed price, which is defined so as to allow them to recover their capital and fixed costs. Consequently, the expected price does not affect VRES profitability, nor investments in VRES. Without FiTs, lower prices lead to lower investments (loops B5 and B6), as for other technologies. In this paper we assume that, until 2035, VRES are supported by FiTs and grow according to a planned expansion in order to meet government targets. After 2035, investment decisions in VRES are endogenous and based on their profitability, which depends on market prices.

The expected profitability of other technologies is affected by expected future capacity of all technologies, including VRES. Since electricity markets are dispatched by merit order and VRES have marginal costs close to zero, the same demand can be met by generation with lower variable costs, resulting in a lower clearing price. A reduction in the expected price will affect other technologies' profitability, discouraging investments in new capacity. Peak units (CCGT and hydro-storage) are particularly affected since larger amounts of VRES generation not only reduce prices, but also the residual demand (demand minus the production of VRES). Hence, generation needed from CCGT and hydro storage, and thus their operating hours, decrease. Consequently, their expected LCOE increases which, together with lower prices, decreases their expected profitability.

\footnotetext{
2 The levelized costs of electricity (LCOE) consider capital and operational costs and are expressed in money/electricity generation, i.e., $\mathrm{CHF} / \mathrm{kWh}$. The operational costs are easily assessed in these units. When assessing the capital cost per unit generated for a future plant, it is necessary to calculate the Full Load Equivalent Operating Hours (FLEOH) of the plant. As the plant incurs costs throughout its lifespan, it is necessary to take the present value of all the annualized costs.
} 
We assume that imports compete with local generation. Thus, the country imports either because local capacity is not sufficient to meet local demand or because the price of imports is below that of other alternatives (merit order dispatch). The possibility to import increase the expected supply, which might decrease prices. Appendix A provides a detailed model description, including the model equations.

We run the simulation from 2014 to 2050. For each quarter (season) we simulate a representative day. For each representative day, hourly demand shapes for each season are estimated using historical data from 2009-2013. This allows us to capture the hourly and seasonal patterns of supply and demand, both of which are important given the low shortterm elasticity of demand and the non-storability of electricity. To fit the Swiss hydrological pattern, seasons are defined as follows: January-March (winter), April-June (spring), JulySeptember (summer) and October-December (autumn). Following the SFOE (2013), we assume an increasing demand (on average 0.5\%/year) for our base case, labelled business as usual $(B A U)$. Other demand scenarios proposed in SFOE (2013) are considered later. This estimation of demand includes neither losses nor pumping consumption, which are thus added to build the hourly demand estimations. Losses are assumed to be $8 \%$, according to historical data (SFOE, 2014b). During simulation, pumping and natural inflows are assumed to increase proportionally to pumping and hydro-storage generation capacity, respectively. The model is initialised (2014) using the average seasonal values from 2009 to 2013.

We consider 7 technologies, whose initial capacities and expansion potential, i.e., the maximum they can expand, are specified in Table 2. Our model implements the government objectives of VRES generation: 4.4 TWh by 2020 and 14.5 TWh by 2035 (The Swiss Federal Council, 2013). We thus assume a planned expansion over the simulation horizon of PV and wind energy, proportional to their expansion potential. Given the potentials of PV and wind energy, $90 \%$ of the 4.4 TWh must be met by PV in 2020. The availability factor of PV, being 
$11 \%, 4,110 \mathrm{MW}$ of capacity are needed to produce $3.96 \mathrm{TWh}(90 \%$ of $4.4 \mathrm{TWh})$ in 2020 . We perform similar calculations for the 2035 objective and for wind energy. The FiT values specified in the Energy Act have been modified several times since their initial implementation in 2009. We thus set the FiTs so as to cover the expected LCOE of each technology, under the assumption that FiTs last 20 years, as is currently the case. Investments after 2035 are determined by their profitability and are limited by their remaining potential.

After the Fukushima accident in March 2011, the Swiss Federal Council announced the phase-out of nuclear plants after 50 years of operation, i.e., between 2019 and 2034 (The Swiss Federal Council, 2011). This was a major commitment because nuclear capacity equalled 3,278 MW in December 2013, accounting for 18\% of total capacity. The Parliament is currently reconsidering this decision. Mühleberg (373 MW) should be decommissioned in 2019, as the investments needed are financially non-viable. Biznau I and II (365 MW each) will be decommissioned after 60 years of operation, in 2029 and 2032, respectively. Gösgen (985 MW) and Leibstadt (1190 MW), the more recent plants, can initially operate for 60 years, until 2039 and 2044, and request successive 10 year extensions, which will be granted if the security conditions are fulfilled (Le Temps, 2014). However, the future of nuclear power remains uncertain as at the same time, a referendum demanding that all plants be decommissioned after 45 years of operation is being launched (Swiss Confederation Administration, 2013).

In our base case scenario $(B A U)$ we assume what currently seems to be the most likely scenario: Muhleberg being decommissioned in 2019 and the others plants being decommissioned after 60 years of operation. We also assume that hydro projects currently under construction will come online at their scheduled start of operation (SFOE, 2014c). 
The market is dispatched according to the marginal costs of the different technologies (see Table 2), and the prices of imports, both of which are exogenous. Hydro-storage bids at its opportunity costs, which are a function of the reservoir level and the prices of other producers. Fossil-fuel generation includes CCGT and other thermal, (mainly cogeneration plants (CHP)). The costs of these plants depend on fuel and carbon prices; their marginal cost is assumed to increase step-wise according to the Poyry (2012a) forecast. The marginal costs of the other technologies are assumed constant over the entire simulation. We use capital costs, fixed costs, marginal costs, and the expected load factor to calculate the LCOE in the model. Annual fixed costs are given in Table 2 and capital costs in Figure 3.

Cross-border transmission capacity remains fixed at 7,500 MW for imports. We consider two types of imports: long-term imports based on existing contracts and balancing imports. Longterm imports availability is assumed to decrease progressively from $27 \mathrm{TWh} / \mathrm{year}$ in 2014 to zero in 2040, when these contracts will expire. We assume step-wise decreases according to AES (2012). Their cost is assumed to be $35 \mathrm{CHF} / \mathrm{MWh}$, which lies within the range of costs of nuclear plants found in literature (Boccard, 2014; Lévêque, 2014). Balancing imports are traded in the spot market and their availability equals the difference between the imports transmission capacity and the available long-term import contracts. Hence, the expiration of long term import contracts increases the transmission capacity availability for short-term imports (see more detailed explanation in Section 6A). Balancing import and export prices are exogenous. For each representative day, we built a curve of import prices based on 20122013 historical data from France and Germany (97\% of imports come from these countries). Likewise, we build hourly demand curves as a function of price for Italy, Germany and France, the countries to which Switzerland exports. As balancing imports and long-term imports are considered as additional technologies when clearing the Swiss market (meeting 
local and export demand), imports and exports can occur simultaneously, but not to the same country. We run our simulation in Vensim ${ }^{\circledR}$ DSS 6.1.

The model was calibrated using publicly available data, mainly from the SFOE, the Swiss Federal Council, the Swiss Utilities Association (AES), the International Energy Agency (IEA), the European Power Exchange (EPEX SPOT), the Swiss Transmission System Operator (Swissgrid) and the Italian System Operator (GME). Other sources included Boccard (2014), Kannan and Turton (2012), and reports from the management consulting company Poyry and the Fraunhofer Institute for Solar Energy (ISE). The impact of VRES inherent variability on grid stability is beyond the scope of this paper as balancing the load from VRES should not be a problem given the large hydro-storage capacity, which is very flexible.

We use the classical SD validation tests (Sterman, 2000). The model's equations correctly represent the structure presented in the causal diagrams and are dimensionally consistent, while results of the model are coherent under extreme conditions. We have also performed an extensive sensitivity analysis, which is summarised at the end of Section 3.

\section{RESULTS}

We perform a long-term simulation of the Swiss electricity market, focussing on the impact of the nuclear phase-out and the increasing penetration of VRES on SoS. A thorough analysis of SoS requires considering multiple dimensions (Larsen et al., 2015), which could in the medium to long-term affect the continuity of supply. The three core elements of SoS we focus on are capacity adequacy, imports dependency and price. 
The total available capacity grows from $19 \mathrm{GW}$ at the start of simulation to a maximum of 33 GW in 2035 (see Figure 4). Recall that VRES expansion until 2035 and nuclear decommissioning are exogenous. PV capacity increases from 755 MW in 2013 to 14,436 MW in 2035, and has the highest absolute growth among all technologies; wind energy capacity grows from $60 \mathrm{MW}$ to 917 MW between 2013 and 2035. There are no further investments in these technologies after 2035, when FiTs for new projects are no longer available. In the absence of new investments, capacity of both PV and wind energy decreases from 2035 onwards as a consequence of obsolescence.

There are no investments in other technologies during the entire simulation horizon beyond the investments already committed to. For instance, hydro-storage generation capacity increases significantly in 2016 and 2017, when respectively Nante de Drance (900 MW) and Limmern (1,000 MW) are scheduled to start operating (SFOE, 2014c). Both hydro-storage and run-of-river capacity remain constant after 2017. As a result of the massive retirements due to nuclear phase-out and the obsolescence of mainly VRES, total installed capacity decreases to $18 \mathrm{GW}$ by 2050 .

The changes in capacity mix also affect the amount and mix of electricity generated (

Figure 5). From 2037 onwards the country is always a net importer (Figure 6). The situation deteriorates further in 2039 when Gösgen is decommissioned; net imports reach $33 \mathrm{TWh}$ at the end of simulation (44\% of national consumption). In comparison, over the 1993-2013 period, maximum net imports equalled 6.4 TWh in 2005, and in only 4 years out of 21 did imports exceeded exports. This dependency is exacerbated in winter, when net imports average $51 \%$ of national consumption in the $2041-2050$ period. Nuclear generation is thus partially replaced by PV, but the gap left by the last nuclear plant (2044) is mostly filled by imports. 
The availability of imports reduces the loss of load expectation (LOLE) (Baritaud and Volk, 2014). Also, purchases could be made at prices below those of national producers. However, such a dependency is risky. Imports might be cut by neighbours for political reasons or due to extreme weather conditions. For instance, in case of extremely cold weather, the supply in Switzerland would be seriously endangered if France and/or Germany lacked excess capacity. Besides geopolitical and climate factors, a large dependency might be politically unacceptable. Furthermore, dependency can have a negative impact on investments in the long-term (Ochoa and van Ackere, 2009).

An increasing dependency on imports is not the only element affecting future SoS in Switzerland. While one might expect prices to decrease due to the larger share of zeromarginal cost sources (PV and wind), we observe the opposite: the electricity price increases from $40 \mathrm{CHF} / \mathrm{MWh}$ in 2014 to $57 \mathrm{CHF} / \mathrm{MWh}$ in 2050 (Figure 7). The annual average price initially remains around $40 \mathrm{CHF} / \mathrm{MWh}$, then increases slightly until the decommissioning of the last two nuclear plants (2039), and increases sharply over the next 7 years. According to our model, prices are expected to increase in Switzerland because of the changing generationmix: nuclear energy is replaced by less expensive technologies such as PV and wind, but also by more expensive sources such as balancing imports.

This increase is mainly driven by prices in autumn and winter, when there is little (noon) or no (evening) solar generation when demand peaks (see results of winter in Figure 8). The price increase during the peak hours is higher in the evening than at noon. The decommissioning of nuclear plants has increased the ratio between peak load and base load, and the country has become dependent on balancing imports to meet both the noon and evening peaks. However, as there is some solar energy at noon, prices are lower than in the 
evening. Such higher evening peak prices and lower noon prices have already been observed in the German market since 2011, resulting from the larger penetration of PV.

The increasing price and RPC (fee aimed at covering FiTs for VRES) will certainly lead to higher tariffs. We distinguish tariffs from prices in that the former comprises wholesale prices and other levies included in consumers bills, while the latter refers exclusively to the wholesale price. We thus compute tariffs by aggregating wholesale prices (energy prices), transmission and distribution network levies (which are assumed to equal those of 2014), other public levies and RPC fees. The total levies are assumed to equal $135 \mathrm{CHF} / \mathrm{MWh}$ for the residential and the commercial sectors, and $85 \mathrm{CHF} / \mathrm{MWh}$ for the industrial and the transportation sectors, according to the regulated fees for 2014 (ElCom, 2015). Household tariffs are assumed for the service sector, while industry tariffs are assumed for the transportation sector.

The model generates prices based on the computed dispatch and exchange clearing, while RPC is calculated as follows. Based on capital and fixed costs, and investors' required return, the total cost of FiTs (PV and wind energy) is estimated exogenously at 105 CHF billion. To reflect government policy we assume that the RPC fee progressively increases until 2030, remains stable between 2030 and 2040 and gradually declines to zero by 2050 . The RPC fee is recalculated each quarter to account for the change in demand and the revenues from renewable energy sales. RPC thus increase progressively from $10 \mathrm{CHF} / \mathrm{MWh}$ (defined by the Swiss Energy Act for 2015) to a maximum of $58 \mathrm{CHF} / \mathrm{MWh}$ in 2030 in BAU. This increase is realistic if one compares it for instance with Germany, where the fee paid by households to support renewable energies soared from $3 € / \mathrm{MWh}$ in 2000 to $63 € / \mathrm{MWh}$ in 2014 (BMWi, 2014). Figure 9 illustrate that under these assumptions household and industry tariffs in the BAU scenario increase respectively by $32 \%$ and $38 \%$ over the period $2014-2030$ period and decrease after 2040. 
In general, we can conclude that all scenarios point to increasing net imports and prices, which increases dependency and decreases affordability. These signals warn about the unsustainability of the system. In particular, the increasing dependency can be interpreted as a symptom of inadequate investments in new capacity.

We now turn to a more detailed analysis of the capacity adequacy. Capacity adequacy has traditionally been measured by the reserve margin, which depends on the ratio between capacity and annual peak demand. This measure is appropriate for systems relying mainly on thermal and nuclear generation, in which technologies' availability is close to $100 \%$ or hydrothermal systems in which seasonality of hydro is less pronounced. Given the increasing role of VRES, whose average availability is considerably more limited, the de-rated capacity margin, which allows measuring the system's capacity to meet annual peak demand, is increasingly preferred as capacity adequacy measure (OFGEM, 2013; Royal Academy of Engineering, 2013). However, this measure could be misleading in some cases. For instance, countries with a significant share of hydro-storage generation might overestimate their capacity adequacy. A very high de-rating factor ( $80 \%$ or more) is usually assumed for this technology, ignoring a possible winter shortage.

We propose an alternative metric, the annual energy margin, defined as the ratio between excess energy and annual domestic demand. The excess energy is calculated as the difference between the total hydro-storage availability (including pumping) and the annual unmet demand. The latter is estimated as follows. For each hour, we calculate the demand that cannot be met by technologies other than hydro-storage (hourly unmet demand). These are summed to calculate the annual unmet demand. A detailed description of both the de-rated and the annual energy margin are given in the Appendix B. Note that when energy available from non-hydro-storage technologies exceeds domestic demand, this excess can be stored by 
pumped-storage plants (PSP), thus increasing total hydro-storage availability. This hydrostorage is also available to cover the annual unmet demand.

The energy margin thus captures the seasonal patterns of intermittent sources and the actual availability of hydro-storage generation, incorporating the idea that this technology could perform as a battery. We evaluate the de-rated margin and the energy margin under three scenarios of nuclear phase-out: the current $B A U$, a scenario in which the last two nuclear plants receive operation extensions that go beyond our simulation horizon (NucInd), and a scenario which assumes that the initiative to close all nuclear plants after 45 years is successful (Nuc45). Assuming a referendum in 2015, Muhleberg would close in 2015, and the others would close between 2015 and 2029.

As was shown in Figure 4, in the $B A U$ case total capacity largely exceeds peak demand; however, the de-rated margin never exceeds $30 \%$ (Figure 10). It is important to recall that the de-rated capacity margin is calculated as spare de-rated capacity divided by total de-rated capacity. Between 2014 and 2018 the de-rated margin increases from $20 \%$ to $27 \%$ as the two large hydro-power plants currently under construction start operation. Afterwards, the derated margin gradually decreases to a minimum of $-5 \%$ in 2050. In BAU and NucInd de-rated margins are identical until 2040, but afterwards the $B A U$ de-rated margin in $B A U$ decreases sharply due to the decommissioning of the last two nuclear plants. In $N u c 45$, the de-rated margin is below the other two scenarios until 2045; afterwards it equals that of $B A U$, as the generation-mix is the same. Negative margins, as in Nuc45 and $B A U$, do not imply black-outs as the country can rely on imports. However, they show that even if water is saved to satisfy demand at this time, installed capacity is insufficient.

There is a negative exponential relationship between the de-rated margin and the loss of load expectation (LOLE). For instance, according to OFGEM (2013), a de-rated margin of $4 \%$ 
could result in 3 hours per year in which supply is expected to be lower than demand in UK. This does not mean that users are disconnected: the system operator may implement mitigation actions, e.g., voltage reduction, to solve the problem without disconnecting any consumers. Although this estimate corresponds to the capacity assessment of the UK and cannot be extrapolated to Switzerland, it gives some insight into the risk of having such a low de-rated margin. Reliability standards vary significantly across countries, e.g. 3 hours in France and 18 hours in Belgium (OFGEM, 2013).

The annual energy margin captures the medium-term capacity adequacy improvements resulting from the addition of PV, but Figure 11 shows a much less reassuring long-term picture for the three scenarios in the long-terms. For instance, while the $B A U$ de-rated margin showed a downward trend from 2019 onwards, the energy margin follows an up-ward trend until 2028. This is due to the large amounts of PV being installed, which are not considered in the de-rated margin. Although it is clear that PV cannot be used to meet annual peak demand, PV at noon allows hydro-storage to remain out of the merit-order or even pump, increasing its availability during the evening peak. The energy margin is thus a more appropriate metric to assess a country's capacity adequacy in the presence of VRES. Still, one should be aware of the implicit assumption that reservoirs are large enough to store water from one season to another.

In $B A U$, the annual energy margin turns negative after 2038. This means that even with optimal reservoir management, the total amount of electricity available is insufficient to cover annual demand. Again, this does not necessarily imply blackouts, but the country must rely on imports to satisfy local demand. Thus, dependency after 2037 (recall Figure 6) onwards is due to the unavailability of local sources to meet national consumption: investments in PV are insufficient to cover the increasing demand in the absence of a third of the nuclear power. 
The BAU and NucInd energy margins are identical until the decommissioning of the last nuclear plants in the $B A U$ scenario. The exit of the third part of nuclear capacity by 2033 leaves the country with insufficient resources to meet domestic demand; however, imports are sufficient. Although balancing imports increase prices, the rise is insufficient to trigger investments in new capacity. The system thus perpetuates its imports dependency.

The scenario Nuc45 has the lowest energy margin, as expected. The margin turns negative in 2015, as the closures of Muhleberg and Biznau I have not been anticipated. The margin remains stable between 2016 and 2024 because of the two new large hydro-storage plants and the installation of PV. Two further drops occur in 2023 and 2028, as the remaining nuclear plants close. The margin reaches an all-time low in 2050 (-44\%), i.e., net imports cover at least $44 \%$ of national consumption (without considering pumping consumption).This implies that, assuming an annual availability factor of 90\%, 4,200 MW of CCGT would need to be installed to achieve self-sufficiency by 2050 .

In summary, we can say that while the system deteriorates following the decommissioning of the first three nuclear plants in all three scenarios, it is the decommissioning of the last two plants that creates a critical situation. Whatever the decommissioning scenario, there are no investments in CCGT: their high marginal costs relegate these plants to the role of marginal producers, unable to recover their fixed costs. Marginal costs are particularly high after 2030 because of the $\mathrm{CO}_{2}$ price assumption (see Figure 12). This lack of investments is problematic as CCGT is generally considered to be the most likely replacement for nuclear plants.

Since CCGT would produce at peak times, mainly to export, we run multiple combinations of $\mathrm{CO}_{2}$ prices and Italian prices to identify favourable conditions for CCGT investments. We identify two scenarios in these are profitable, labelled $C O A$ and $C O B$. In $C O A$ we assume that the $\mathrm{CO}_{2}$ price remains at $36.6 \mathrm{CHF} /$ ton $\mathrm{CO}_{2}$ after 2023 and that the Italian prices increase by 
$30 \%$, while in $C O B$ the $\mathrm{CO}_{2}$ price remains in $28.0 \mathrm{CHF} /$ ton $\mathrm{CO}_{2}$ for the entire simulation (see Figure 12) and Italian prices increase by $20 \%$. In both scenarios investments become profitable when the fourth nuclear plant closes (see Figure 13). This highlights that it is important for potential investors to know with certainty, with a reasonable lead time, when nuclear plants will close.

Since Italian prices are more likely to decrease than to increase in the medium-term, CCGT will not be profitable unless there is either a technological breakthrough in CCGT and/or a decrease in gas or $\mathrm{CO}_{2}$ prices. Alternatively, programs aimed at supporting CCGT (e.g., subsidising investments in carbon capture and storage (CCS) technology) could be considered. An analysis of future fuel and $\mathrm{CO}_{2}$ prices is beyond the scope of our work. These are traded in international markets, subject to political and geopolitical factors.

To assess the robustness of our results we perform a detailed sensitivity analysis with respect to, among others, prices of neighbouring countries (which affects their wiling ness to pay for imports from Switzerland and the price of volumes exported to Switzerland), their available volumes for exporting to Switzerland and their desired import volumes from Switzerland; responsiveness of demand to tariffs, the cross-border import capacity, and the costs of the different generation technologies. The main results are summarised below

First, we consider variations between $-30 \%$ and $30 \%$ in German (main source of net imports in Switzerland) and Italian (main destination of net exports from Switzerland) prices, which could occur due to changes in their energy mix and have significant consequences for Switzerland. The two countries have currently a large penetration of VRES (around 15\%). Note that these prices not only affect the price that Switzerland pays for imports (in the case of Germany), but also the two countries' (Italy and Germany) willingness to pay for imports from Switzerland. 
While import and export volumes are not sensitive to changes in the German prices, a 30\% price change in Germany results in a $10 \%$ price change in Switzerland, because balancing imports are usually the marginal producer in the Swiss market. Exports do not vary since the difference between Italian and German prices is so large, that exports to Italy remain profitable. Our results are robust to changes in Italian prices between $-20 \%$ and $+30 \%$. However, for larger drops (-30\%), imports and exports decrease by about $10 \%$, because of Italy's lower willingness to pay for imports from Switzerland. Net imports remain unchanged.

We observe that, regardless of the scenario, prices are expected to increase. This increase leads to a rise in tariffs, which in turn could affect consumption. In the case of Switzerland, assessing this impact is difficult due to the limited information about consumers' response to tariff variations, i.e., demand elasticity. We have therefore taken two different approaches to perform a sensitivity analysis with respect to our demand hypothesis: considering different demand scenarios (with implicit demand management) and modelling a tariff-dependant demand.

Aside from the demand assumed in BAU, the (SFOE, 2013) considers a scenario in which demand remains mostly stable $(D S)$ and a scenario in which demand decreases compared to 2014 level $(D D)$, as shown in Figure 14. Both scenarios implicitly consider some demand management measures. When simulating our model with the $D S$ and $D D$ demands, average prices are respectively $5 \%$ and $8 \%$ below those of the $B A U$ scenario (Table 3 ). While the country eventually becomes a net importer in the three scenarios, the timing depends on the demand assumptions: 2037 in $B A U, 2039$ in $D S$ and 2041 in $D D$. Also, the increase in net imports after the fourth nuclear plant is decommissioned is more limited in $D S$ and $D D$ than 
in $B A U$. Overall, as expected, measures aimed at decreasing demand lead to import dependency, while making electricity more affordable.

Next we consider an extreme scenario where demand in Switzerland is highly sensitive to changes in tariffs. More specifically, based on a comparison between the $B A U$ and $D D$ scenarios (SFOE, 2013) we assume that a sharp increase in tariffs could cause long-term demand to decrease by as much as $28 \%$. In this scenario, demand is endogenous to the model and depends on the simulated tariff.

Modelling demand as an endogenous function of tariffs also has a significant impact on international exchange volumes. In this scenario the country only becomes a net importer in 2044, compared to 2037 in $B A U$. The lower demand also leads to lower prices, but RPC is higher as total FiTs costs must be recovered from a lower volume of demand. Tariffs are slightly higher than in $B A U$ (up to $7 \%$ for households and $9 \%$ for industry). Industry and household tariffs peak in 2038 at respectively $45 \%$ and $31 \%$ above 2014 tariffs. However, evidence from Germany, where demand did not decrease despite a 58\% and $113 \%$ tariffs increase for households and industry respectively over the 2000-2013 period (BMWi, 2015), suggests that such a significant demand decrease, as simulated here, is unlikely. This scenario should thus be interpreted as an upper bound on potential changes in demand.

The next sensitivity analyses concern capital, fuel and $\mathrm{CO}_{2}$ costs. First we assume a 20\% decrease in capital costs for PV, for wind and for both. In these scenarios the country achieves its renewables target earlier as we assume that the fund aimed at supporting VRES remains unchanged. However, this leads neither to changes in prices, nor in electricity exchanges.

Next we consider a scenario without FiTs for new VRES plants (labelled NoFiTs), i.e., achieving the 2020 and 2035 targets is left in the hands of the market, and investment 
decisions are based on VRES expected profitability. Under this assumption there are no investments in VRES: prices are too low to cover capital expenses. Compared to $B A U$, net imports increase by $150 \%$, mainly because exports decrease significantly. Wholesale prices are also higher in NoFiTs as the lower available capacity results in a tighter margin. However, tariffs are lower as the absence of an RPC levy (aimed at covering a total of CHF 105 billion) more than offsets the higher prices (extra cost of CHF 8 billion). Finally, our sensitivity analysis indicates that imports, exports and prices are not sensitive to fuel and $\mathrm{CO}_{2}$ cost variations between $-30 \%$ and $30 \%$.

Finally, we turn to the cross-border import capacity, which in the $B A U$ scenario is constraining at peak hours, with congestion increasing over the simulation period. To evaluate the impact of this constraint, we run a scenario in which, following the ENTSO-E (2014) forecast, cross-border transmission capacity for imports is assumed to increase from 7,500 MW in 2016 to 10,000 MW in 2020. In this scenario, labelled EXP, imports are higher than in $B A U$ (recall Figure 6), particularly towards the end of the simulation period, where imports in EXP exceed those of $B A U$ by $12 \%$.. Exports are higher in EXP than in $B A U$ because the higher availability of imports increases the country's ability to export. More precisely, the increase in off-peak imports allows shifting hydro production from off-peak to peak-times which, together with the increase in peak imports, enables Switzerland to increase exports to Italy. Consequently, net import volumes are very similar in the two scenarios. These higher imports replace more expensive local production, resulting in lower prices (on average $11 \%$ lower over the 2040-2050 period, see Figure 7). Cross-border expansion thus improves the country's SoS as it provides access to cheaper electricity, without increasing dependency.

As the availability of such imports is uncertain, we also tested the impact of reducing Switzerland's maximum hourly trade with France and Germany (under $B A U$ assumptions). 
Total imports and exports are insensitive to a reduction of up to $30 \%$ due to Switzerland's large storage capacity: increased off-peak imports allow hydro-storage generation to compensate the shortage of imports at peak time, and exports to Italy are not affected. If import capacity is reduced by more than 30\%, shortages occur from 2045 onwards. This results in significantly higher prices, which make CCGT investments profitable.

These sensitivity analyses allow us to conclude that our results are robust to reasonable changes in parameter values.

\section{CONCLUSION AND POLICY IMPLICATIONS}

The proposed model allows us to simulate the Swiss electricity market and, in particular, the impact of the nuclear phase-out and the incentives for VRES (mostly for PV) to partially replace nuclear power. While the country has historically been a net exporter, creating a surplus for Swiss utilities, our results indicate that imports are bound to increase significantly in the future; in all scenarios the country sooner or later becomes a net importer. Import dependency is expected to be particularly critical in winter.

These changes in the energy mix and exchange patterns cause prices to rise which, together with the RPC, cause tariffs to increase. The higher dependency on imports and the tariff increases highlight a capacity adequacy problem. We introduce a new metric, the annual energy margin, to assess the impact of investment decisions on capacity adequacy, and discuss its advantages compared to the de-rated margin. In the three scenarios of nuclear phase-out, the energy margin gives a less reassuring picture than the de-rated margin. Our results show that the generation capacity adequacy deteriorates to a level where the country is no longer capable of meeting domestic demand. Even when the last two nuclear plants are 
assumed to remain operational beyond a 60 years lifespan, available energy is insufficient to meet annual demand.

Our model thus helps to understand the new challenges that a large(r) capacity and output of VRES pose to regulators, and how this evolution can jeopardise SoS in electricity markets. In particular, the price-lowering effect of VRES has been widely discussed in the literature. Although the penetration of VRES increases significantly in the Swiss market, our simulations do not indicate a price drop, due to the cost of the sources that replace nuclear power. The impact of VRES and of the nuclear phase-out thus cannot be analysed separately. Import dependency and price rise are tightly interrelated and our results suggest that both are symptoms of a decreasing capacity adequacy.

Since the IEA (2014) refers to energy security as the uninterrupted availability of energy sources at an affordable price, we can conclude that the $\mathrm{SoS}$ in the Swiss electricity market is seriously threatened by this import dependency and the decreasing availability of energy, as well as by the significant tariff increases. This large dependency affects utilities' revenues and makes the country vulnerable to climatic and geopolitical risks.

Simulated imports and exports are sensitive to large drops in Italian prices. Historically, Italian prices have been significantly higher than in the rest of Europe. As the Italian market is changing (e.g., encouraging investments in VRES and renegotiating gas contracts), its prices are likely to decrease in the future. France's and Germany's available export volumes are dependent not only on technical and economic factors, but are also subject to political decisions. A major drop in these volumes (in excess of 30\%) would significantly affect Swiss prices and CCGT investments.

Following the acceptance of a referendum on February $9^{\text {th }}, 2014$, the EU has unilaterally suspended negotiations on the entry of Switzerland in the European single energy market. 
This, together with the political unpopularity of such imports dependency, is leading the country to review its energy policy, in particular regarding nuclear power plants and the constraints on the expansion potential of hydro-power. The recent parliamentary proposal to allow four nuclear plants to operate for 60 years (with the possibility of an extension for two of them) shows that the Swiss politicians are aware that abandoning nuclear energy in the middle-term endangers self-sufficiency.

Policy should thus focus on sending adequate signals to investors so as to at least limit imports dependency. Under current policy, prices seem inadequate to encourage investments in hydro-storage, a reliable and clean technology, in order to fil the gap left by nuclear energy. Likewise, investments in CCGT are not profitable in the $B A U$ scenario; lower $\mathrm{CO}_{2}$ prices and/or a higher Italian willingness to pay for imports from Switzerland would be required. Furthermore, in those cases in which CCGT are profitable, investments only occur shortly before the nuclear phase-out completion. The lack of CCGT investments is particularly critical after the decommissioning of the fourth nuclear plant. Therefore, if the country really is committed to closing down all the nuclear power plants, it is essential to provide attractive conditions, including adequate infrastructure, incentives aimed at improving plant efficiency and/or reducing emissions, and a stable regulatory framework, so as to trigger investments in CCGT.

Supporting this technology might not be the most environmentally friendly alternative and could imply higher costs for the system, and in turn, for consumers, but it seems to be the only alternative given the current strong legislation concerning water flows. Still, this technology is likely to face strong opposition from the population. Given the Swiss direct democracy system, the population can delay and potentially block any policy the government might want to implement; this is an additional source of uncertainty for investors. 
The population might also object to the expected tariff rise resulting from the support for renewable energies. Still, these potential additional costs might be justified in order to avoid a much more costly blackout. A 2008 study by the SFOE estimates the costs resulting from a blackout in Switzerland at between CHF 8 and 30 million per minute. For a day-long power outage, the estimate is between CHF 12 and 42 billion (without including the damage to Switzerland's reputation as a business location) (Credit Suisse, 2013). In comparison, our model assumes that the investment necessary to support VRES is of the order of CHF 105 billion. The resulting price decrease s partially offsets the cost of these subsidies. Although total costs for consumers are higher in the scenario with incentives, policy maker should also consider that a scenario with FiTs leads to significantly lower dependency.

Another issue affecting dependency is market integration and cross-border capacity expansion. Our results show that if imports transmission capacity is expanded, prices would decrease, but import dependency would increase further. These issues illustrate the complex problem that the policy makers face: incentivising green technologies to meet environmental commitments, without discouraging investments in other technologies, so as to limit imports dependency.

Our model has several limitations. First, we assume that pumping will follow the same pattern as during the 2009-2013 period. However, changes in the generation-mix might affect this pattern: while higher price differences between peak and off-peak prices could enhance arbitrage opportunities and lead to more pumping, dismantling nuclear plants could significantly reduce the availability of cheap energy to pump. Another model boundary issue relates to the interaction with neighbouring markets. Our results are robust to realistic changes in German and Italian prices. However, since demand for exports from Switzerland is calibrated using historical data, our model can only partially capture the consequences of a significant expansion of cross-border transmission capacity. 


\section{ACKNOWLEDGEMENT}

We gratefully acknowledge support from the Swiss National Science Foundation, Grant CR12I1_140740.

\section{APPENDIX}
A. Model description

\section{Dynamics of capacity}

Installed capacity $K_{T, t}$ of each technology increases as new capacity comes online $\left(E K_{T, t}\right)$ and decreases through obsolescence $\left(O K_{T, t}\right)$.

$$
\frac{\partial K_{T, t}}{\partial t}=E K_{T, t}-O K_{T, t}
$$

Obsolesce is defined as the aggregated obsolescence of old projects and new projects as shown in Eq. (3). Old projects are those installed before 2013 that remain installed at time $t$ $\left(\operatorname{Old} K_{T, t}\right)$. This capacity becomes obsolete depending on its lifespan $\left(L_{T}\right)$. We do not use a decommission schedule for old projects as we do not have specific information about when each plant will be decommissioned. Obsolescence of old projects, $\operatorname{OldK}_{T, t}$ is defined as

$$
\frac{\partial O \operatorname{ld} K_{T, t}}{\partial t}=\frac{O \operatorname{ld} K_{T, t-1}}{L_{T}}
$$

New projects correspond to the capacity coming online between 2014 and $2050\left(E K_{T, t}\right)$. These become obsolete at the end of their lifespan. 


$$
O K_{T, t}=\frac{O l d K_{T, t}}{L_{T}}+E K_{T, t-L_{T}}
$$

We consider specific obsolescence conditions for hydropower and nuclear energy. We assume that hydro-storage and run-of-river capacity do not become obsolete but are refurbished to remain online without important losses of efficiency. We also assume that nuclear is decommissioned according to a fixed schedule, represented by the variable $O K_{T, t}$.

Capacity under construction $\left(U K_{T, t}\right)$ increases by capacity starting construction $\left(C K_{T, t}\right)$ and decreases by the projects that start operation $\left(E K_{T, t}\right)$.

$$
\frac{\partial U K_{T, t}}{\partial t}=C K_{T, t}-E K_{T, t}
$$

New capacity results from the projects that started construction $\left(C K_{T, t}\right)$ and come online after a delay equivalent to the construction time, $\operatorname{Cons} D_{T}$, which is technology-dependent.

$$
E K_{T, t}=C K_{T, t-C o n s D_{T}}
$$

\section{Market clearing}

To compute the day-ahead auction for each hour of a representative day of each quarter, available supply and bid prices from producers are needed. Supply from producers comes from generation by the different technologies $T$ considered and from imports. The latter might be of two types: long-term contracts (LTI) and balancing imports (BI). The availability of imports from LTI is exogenous based on the estimations of AES (2012). The availability of LTI and BI per hour is presented in Figure A1. 
We thus estimate the availability of imports from balancing markets as the remaining available capacity from the cross-border capacity, which is assumed to be 7,500 MW during the entire simulation.

$$
A_{B I, h, t}=7500-A_{L T I, h, t}
$$

The available supply from local technologies $\left(S_{T, h, t}\right)$ depends on the availability factor $\left(A_{T, h, t}\right)$ of each technology during each hour $h$ and on the installed capacity $\left(K_{T, t}\right)$.

$$
S_{T, h, t}=K_{T, t} \times A_{T, h, t}
$$

Marginal costs of producers $\left(M C_{j, h, t}\right)$ do not depend on the hour of the day and equal their variable production costs $\left(V C_{j, t}\right)$, except for hydro-storage and balancing imports, as shown in Eq. (8). In the specific case of long-term import contracts, which refer to the contracts with French nuclear plants, we assume a price (marginal cost) of $35 \mathrm{CHF} / \mathrm{MWh}$.

$$
\mathrm{MC}_{j, \mathrm{~h}, \mathrm{t}}=\mathrm{VC}_{j, \mathrm{t}} \forall j \neq H S, B I
$$

The marginal cost for hydro-storage equals the hydro-storage reservation price, which will be explained in detail later (equations (14) - (17)). The marginal cost of balancing imports equals the weighted average price of the French and German spot markets $\left(E P_{\text {France, }}\right.$ and EP $\left.P_{\text {Germany, } h}\right)$ according to the 2012 and 2013 shares of hourly imports.

$$
M C_{B I, h, t}=F\left(E P_{\text {Germany }, h}, E P_{\text {France }, h}\right)
$$


Recall that we run our model from 2014 to 2050 with a quarterly step, i.e. 147 quarters. For each quarter we run the hourly dispatch of a representative day, i.e., we consider the representative hourly demand of each season. We thus assume that the 90 days of each quarter present the same pattern. The available supply of each producer $\left(S_{j, h, t}\right)$ and their marginal costs $\left(M C_{j, h, t}\right)$ are used to build the supply curve for the hourly dispatch. We run a merit order dispatch according to producers' marginal costs, which yields the quantity $S D_{j, h, t}$ dispatched by each producer. First we compute the local dispatch, i.e., supply from producers is dispatched to cover local demand $D_{h, t}$, which includes the consumption from PSP. We assume $D_{h, t}$ is totally inelastic. Local dispatch is solved as a basic costs minimisation problem as follows:

$$
\min _{S D_{j, h, t}} \sum_{j} M C_{j, h, t} S D_{j, h, t} \quad \forall h, t
$$

Subject to

$$
\begin{gathered}
S D_{j, h, t} \leq S_{j, h, t} \\
D_{h, t}=\sum_{j} S D_{j, h, t}
\end{gathered}
$$

The remaining supply $\left(S R_{j, h, t}\right)$ is then available for exports. It will be used only if the prices in the countries that import from Switzerland exceed the marginal costs of this remaining supply.

$$
S R_{j, h, t}=S_{j, h, t}-S D_{j, h, t}
$$


Similar to the dispatch to cover national consumption, we compute a merit order dispatch for exports. However, unlike the national demand, which is inelastic, exports depend on the neighbouring countries' demand for imports from Switzerland $\left(D E_{c, h, t}\right)$ and their willingness to pay. The former is an exogenous variable and is estimated based on historical data between 2009 and 2013. The latter equals the hourly prices in each country $c$ (Italy, Germany and France), $E P_{c, h, t}$. Exports from producers to each country $\left(E S_{j, c, h, t}\right)$ are calculated by solving a welfare maximisation problem, which allows calculating the clearing price $P_{h, t}$.

$$
\max _{P_{h, t} E S_{j, c, h, t}} \sum_{T, c}\left(E P_{c, h, t}-P_{h, t}\right) \times E S_{j, c, h, t}-\left(P_{h, t}-M C_{j, h, t}\right) \times E S_{j, c, h, t} \quad \forall h, t
$$

Subject to

$$
\begin{aligned}
& \sum_{c} E S_{j, c, h, t} \leq S R_{j, h, t} \\
& \sum_{j} E S_{j, c, h, t} \leq D E_{c, h, t}
\end{aligned}
$$

In the extreme case when the hourly supply (including imports) is lower than the national demand, the price would equal the VOLL, which is assumed to be 3,000 CHF/MWh.

Then, the total quantity supplied $\left(Q_{j, h, t}\right)$ by each producer in a quarter is calculated as follows, assuming 90 days per quarter.

$$
Q_{j, t}=\left[\sum_{h}\left(S D_{j, h, t}+E S_{j, h, t}\right)\right] \times 90
$$

In the case of hydro-storage, the modelling is slightly different to that of other technologies as availability depends on reservoir level; the marginal cost reflects the water opportunity cost. This is modelled as a function of the forecasted maximum reservoir level $\left(F R L_{t}\right)$ as well as of 
the substitutes' price, as presented in Figure A2. The parameters $R 1, R 2, R 3$ and $R 4$ are estimated during model calibration. $O_{H S}$ equals the variable production costs of $\mathrm{HS}\left(V C_{H S, t}\right)$, Vmax and Vmin are respectively the maximum and minimum prices of substitutes (CCGT, TH, LTI and BI), and Vsca is the scarcity price (assumed to be $500 \mathrm{CHF} / \mathrm{MWh}$ ). The scarcity price was also estimated during model calibration. This way of modelling hydro-storage reservation prices is proposed by van Ackere and Ochoa (2010) and Ochoa and van Ackere (2015), and allows modelling the strategic management of water reservoirs, which is crucial in countries highly dependent on hydro-storage.

The variable $F R L_{t}$ captures the expected excess or shortage of water in a quarter. This is calculated in Eq. (14) considering the current amount of water in the reservoir $\left(W_{t}\right)$, the water inflow $I_{t}$ (inflow from natural stream flows and from pumping) and the reservoir capacity $\left(R_{t}\right)$

$$
F R L_{t}=\frac{W_{t}+I_{t}}{R_{t}}
$$

The reservoir capacity $\left(R_{t}\right)$ and the natural inflow evolve proportionally to the increase of hydro-storage generation capacity as presented in Eq. (15). Likewise, the amount of water pumped is adjusted by the increase of pumping capacity.

$$
R_{t}=R_{t 0} \frac{K_{H S, t}}{K_{H S, t 0}}
$$

The stock of water in the reservoir varies from one quarter to another according to hydrostorage production, the water inflow and the spillages $\left(\right.$ Spill $\left._{t}\right)$ : 


$$
\frac{\partial W_{t}}{\partial t}=I_{t}-Q_{H S, t}-\text { Spill }_{t}
$$

Spillages only occur if the stock of water at the end of the quarter exceeds the reservoir capacity.

$$
\operatorname{Spill}_{t}=\operatorname{Max}\left(0, R_{t}+I_{t}-Q_{H S, t}\right)
$$

\section{Investments decisions}

To make investment decisions, each technology calculates its expected profits. These depend on the future capacity and the resulting dispatch. Future capacity $\left(F K_{n, t}\right)$ equals all the capacity already commissioned (i.e., installed capacity $\left(K_{n, t}\right)$ and capacity under construction $\left.\left(U K_{n, t}\right)\right)$, minus capacity that will not be available in 5 years (the maximum time for a plant to come online) because of obsolescence $\left(O K_{n, t}^{*}\right)$ :

$$
F K_{n, t}=K_{n, t}+U K_{n, t}-O K_{n, t}^{*}
$$

Each technology $T$ needs to calculate the future capacity of other technologies and its own future capacity under different capacity investment assumption, i.e., each technology $T$ considers it is the only technology that expands. In other words, when evaluating their expected profitability, a technology $T$ considers already planned expansion of others technologies but not further expansions. This is a realistic assumption as each technology $T$ has incomplete and imperfect information about the others, i.e., they know what is currently under construction but they cannot know the investment decisions of competitors in real time. 
Hence, the forecast of future installed capacity of technology $n$ made by technology $T$, assuming a capacity investment size $e\left(F K E_{n, e, t}^{T}\right)$, considers the capacity already commissioned $\left(F K_{n, t}\right)$ and the expansion being considered $\left(E_{n, e, t}\right)$.

$$
F K E_{n, e, t}^{T}= \begin{cases}F K_{n, t}+E_{n, e, t} & \text { if } T=n \\ F K_{n, t} & \text { if } T \neq n\end{cases}
$$

For each technology $\mathrm{T}$ we define a maximum quarterly capacity expansion $\left(\operatorname{Max} C K_{T}\right)$. Then, to calculate $E_{n, e, t}$ we define 10 sizes, ranging from $10 \%$ to $100 \%$ of $\operatorname{Max}_{C} K_{T}$.

$$
E_{n, e . t}=e\left(\frac{\operatorname{MaxC} K_{n}}{10}\right)
$$

For instance, investments in CCGT vary between 60 and $600 \mathrm{MW}$. Considering more than 10 expansion sizes could increase significantly the computing time without affecting results. Considering different size alternatives is important as, for instance, the minimum size of a CCGT plant is $60 \mathrm{MW}$. This allows us to include these technical constraints and capture the potential effects of the discrete nature of investments.

When computing the dispatch, imports availability and demand 5 years hence are considered. Each technology $T$ calculates the average price it would receive when expanding $\left(P_{e, t}^{T}\right)$. The resulting price is compared to the levelised cost $\left(\operatorname{LCOE}_{e, t}^{T}\right)$ in order to calculate the expected profitability.

$$
X_{e, t}^{T}=\frac{P_{e, t}^{T}}{L C O E_{e, t}^{T}}-1
$$


The $L C O E_{e, t}^{T}$ is calculated in Eq. (22) by each technology $T$ using its annualized capital costs $\left(K C_{T, t}\right)$, annual fixed costs $\left(F C_{T, t}\right)$, variable production costs $\left(V C_{T, t}\right)$ and resulting load factor $\left(E L F_{e, t}^{T}\right)$ when expanding $E_{n, e, t}$. The latter is used to calculate the annualized capital costs and the annual fixed costs per unit of electricity expected to be produced.

$$
L C O E_{e, t}^{T}=\frac{K C_{T, e, t}+F C_{T, t}}{E L F_{e, t}^{T} \times 24 \times 360}+V C_{T, t}
$$

$(24 \times 360$ are the number of hours in a year)

Finally, the largest profitable investment size is selected.

$$
C K_{T, t}=\operatorname{Max}\left(E_{T, e . t} \times W_{e, t}^{T}\right)
$$

where $W^{T}{ }_{e, t}$ is defined as:

$$
W_{e, t}^{T}=\left\{\begin{array}{lr}
1, & \text { if } X_{e, t}^{T}>0 \\
0, & \text { in other case }
\end{array}\right.
$$

Some exogenous variables such as natural water inflows, pumping, hourly demand, hourly prices for exports and imports, and PV and wind availability factors have seasonal (quarterly) patterns. The value thus depends on the season, which is modelled for each quarter t. For instance, the availability factor of PV $\left(A_{P V, h, t}\right)$ equals $A_{P V, h, s}$, where $s$ equals $\bmod (t, 4)$ (see Figure A3). Availability factors of PV and wind energy are estimated from diurnal German power courses of presented in Fraunhoffer ISE (2013) and adjusted using the annual average values for Switzerland presented in Kannan and Turton (2012).

B. Description of generation capacity adequacy metrics 


\section{B.1. De-rated margin}

De-rating factors are used to calculate the de-rated capacity, which is the amount of capacity that is available to meet the annual demand peak. The de-rated margin is calculated as the margin between peak demand and de-rated capacity. Since the demand peak in Switzerland occurs in the winter evening, the de-rating factor of PV is $0 \%$ (see Table B1). The de-rating factor of hydro-storage is significantly higher than its annual availability factor, because water can be saved to meet peak demand. We did not find any estimate for Switzerland; we therefore use the factor calculated for the UK (Poyry, 2012a). The de-rating factors for the remaining technologies equal their availability factor in winter.

\section{B.2. Annual energy margin}

We first calculate the demand that remains unmet after subtracting the total production of non-hydro-storage technologies for each season $s$ at each hour $h$ (Eq. (25)). As explained before, hydro-storage is the only technology $t$ whose production can be shifted from one hour to another because of storability. If aggregated production of other technologies is higher than demand at certain time, this excess cannot be used at another moment unless it is pumped (Eq. (26) $)^{3}$. The additional energy available resulting from pumping is constrained by the pumping capacity $\left(K_{P S P}\right)$ and efficiency $(\rho)$ (Eq. (27)). The aggregated annual unmet demand can only be covered by hydro-storage, whose annual availability depends on the aggregated natural inflows (per season) plus those from pumping. The annual excess energy is calculated as the difference between hydro availability and annual unmet demand. The ratio between excess energy and the domestic demand is used to estimate the annual energy margin (Eq. (28)). A low margin points to an adequacy problem.

\footnotetext{
${ }^{3}$ This approach could be extended to other storage technologies.
} 


$$
\begin{aligned}
& \text { Unmet_demand }_{s h}=\max \left(0, \text { Demand }_{s h}-\sum_{t \neq H S} \text { Generation }_{\text {sht }}\right) \\
& \text { Storable_excess }_{s h}=\max \left(0, \sum_{t \neq H S} \text { Generation }_{\text {sht }}-\text { Demand }_{s h}\right) \\
& \text { Avail_pumping }_{\text {sh }}=\min \left(\mathrm{K}_{\mathrm{PSP}}, \text { Storable_excess }{ }_{\text {sh }}\right) \times \rho \\
& \text { Energy_margin }=\frac{\sum_{\text {sh }} \text { Inflows }_{s}+\text { Avail_pumping }_{s h}-\text { Unmet_demand }_{s h}}{\sum_{s h} \text { Demand }_{s h}}
\end{aligned}
$$

\section{REFERENCES}

AES, 2012. Scénarios pour l'approvisionnement électrique du futur. Rapport global [WWW Document]. Strom.ch. URL http://www.strom.ch/uploads/media/AES_Scenarios-appelectrique-futur_Rapport-global_2012.pdf

Arango, S., 2007. Simulation of alternative regulations in the Colombian electricity market. Socio-Economic Planning Sciences 41, 305-319. doi:10.1016/j.seps.2006.06.004 Arango, S., Larsen, E., 2011. Cycles in deregulated electricity markets: Empirical evidence from two decades. Energy Policy 39, 2457-2466.

Baritaud, M., Volk, D., 2014. Seamless Power Markets. Regional integration of electricity markets in IEA member countries.

BMWi, 2014. Energiedaten: Gesamtausgabe [WWW Document]. BMWi.de. URL http://www.bmwi.de/DE/Themen/Energie/Energiedaten-undanalysen/Energiedaten/gesamtausgabe, did=476134.html (accessed 9.28.14). 
Boccard, N., 2014. The cost of nuclear electricity: France after Fukushima. Energy Policy 66, 450-461. doi:10.1016/j.enpol.2013.11.037

Bunn, D.W., Larsen, E.R., 1992. Sensitivity of reserve margin to factors influencing investment behaviour in the electricity market of England and Wales. Energy Policy 20, 420-429. doi:10.1016/0301-4215(92)90063-8

Confédération Suisse, 2015. Revenus et dépenses des ménages en 2013 [WWW Document]. URL http://www.bfs.admin.ch/bfs/portal/fr/index/themen/20/02/blank/key/einkommen0/niv eau.html (accessed 12.17.15).

Credit Suisse, 2013. Credit Update Switzerland - Initiation of coverage Swissgrid (Low AA, Stable): Powerful connection in Switzerland [WWW Document]. Swissgrid.ch. URL https://www.swissgrid.ch/dam/swissgrid/company/investor_relations/financial_report s/de/CS_Credit_Research_Report.pdf

ElCom, 2015. Site Internet de l'Elcom concernant les prix de l'électricité: Comparez le prix de votre courant [WWW Document]. Commission fédérale de l'électricité ElCom. URL https://www.prix-electricite.elcom.admin.ch/Start.aspx (accessed 12.17.15). ENTSO-E, 2014. Scenario Outlook and Adequacy Forecast 2014-2030. ENTSO-E, Brussels. Filippini, M., 2011. Short- and long-run time-of-use price elasticities in Swiss residential electricity demand. Energy Policy, Sustainability of biofuels 39, 5811-5817. doi:10.1016/j.enpol.2011.06.002

Filippini, M., 1999. Swiss residential demand for electricity 6, 533-538. doi:10.1080/135048599352880

Ford, A., 2002. Boom and Bust in Power Plant Construction : Lessons from the California Electricity Crisis. Journal of Industry, Competition and Trade 2, 59-74. 
Ford, A., 1999. Cycles in competitive electricity markets: A simulation study of the western United States. Energy Policy 27, 637-658.

Ford, A., 1997. System Dynamics and the Electric Power Industry. System Dynamics Review 13, 57-85. doi:10.1002/(SICI)1099-1727(199721)13:1<57::AID-SDR117>3.3.CO;22

Fraunhoffer ISE, 2013. Electricity production from solar and wind in Germany in 2012. Freiburg, Germany.

Gary, S., Larsen, E.R., 2000. Improving firm performance in out-of-equilibrium, deregulated markets using feedback simulation models. Energy Policy 28, 845-855. doi:10.1016/S0301-4215(00)00059-8

GME, 2014. Gestore Mercati Energetici [WWW Document]. URL http://www.mercatoelettrico.org

IEA, 2014. IEA - Energy security [WWW Document]. URL https://www.iea.org/topics/energysecurity/ (accessed 4.30.13).

IEA, 2012. Renewable Energy Outlook, in: World Energy Outlook 2012. International Energy Agency, Paris.

Joskow, P.L., 2006. Introduction to Electricity Sector Liberalization: Lessons Learned from Cross-Country Studies, in: Pfaffenberger, F.P.S. (Ed.), Electricity Market Reform, Elsevier Global Energy Policy and Economics Series. Elsevier, Oxford, pp. 1-32.

Kannan, R., Turton, H., 2012. Cost of ad-hoc nuclear policy uncertainties in the evolution of the Swiss electricity system. Energy Policy 50, 391-406. doi:10.1016/j.enpol.2012.07.035

Labandeira, X., Labeaga, J.M., López-Otero, X., 2012. Estimation of elasticity price of electricity with incomplete information. Energy Economics 34, 627-633. doi:10.1016/j.eneco.2011.03.008 
Larsen, E.R., Bunn, D.W., 1999. Deregulation in Electricity: Understanding Strategic and Regulatory Risk. The Journal of the Operational Research Society 50, 337-344. doi: $10.2307 / 3010451$

Larsen, E.R., Osorio, S., van Ackere, A., 2015. Security of Supply in the Electricity Sector: A framework for evaluation (Working Paper). Lugano.

Le Temps, 2014. Hormis Beznau, les centrales ne se voient pas imposer de durée de vie. Le Temps 8 .

Lévêque, F., 2014. The Economics and Uncertainties of Nuclear Power. Cambridge University Press, Cambridge, United Kingdom.

Lieb-Dóczy, E., Börner, A.-R., MacKerron, G., 2003. Who Secures the Security of Supply? European Perspectives on Security, Competition, and Liability. The Electricity Journal 16, 10-19. doi:10.1016/j.tej.2003.10.008

Lise, W., van der Laan, J., Nieuwenhout, F., Rademaekers, K., 2013. Assessment of the required share for a stable EU electricity supply until 2050. Energy Policy 59, 904913. doi:10.1016/j.enpol.2013.04.006

Madlener, R., Bernstein, R., Alva González, M.Á., 2011. Econometric Estimation of Energy Demand Elasticities (No. Vol. 3, Issue 8), E.ON Energy Research Center Series. E.ON Energy Research Center.

Ochoa, C., van Ackere, A., 2015. Does size matter? Simulating electricity market coupling between Colombia and Ecuador. Renewable and Sustainable Energy Reviews 50, 1108-1124. doi:10.1016/j.rser.2015.05.054

Ochoa, P., 2007. Policy changes in the Swiss electricity market: Analysis of likely market responses. Socio-Economic Planning Sciences 41, 336-349.

Ochoa, P., van Ackere, A., 2009. Policy changes and the dynamics of capacity expansion in the Swiss electricity market. Energy Policy 37, 1983-1998. 
OFGEM, 2013. Electricity Capacity Assessment 2013 (Report to the Secretary of State No. 105/13). London.

Pereira, A.J.C., Saraiva, J.T., 2013. A long term generation expansion planning model using system dynamics - Case study using data from the Portuguese/Spanish generation system. Electric Power Systems Research 97, 41-50. doi:10.1016/j.epsr.2012.12.001

Poyry, 2012a. Angebot und Nachfrage Nach Flexiblen Erzeugungskapazitäten in der Schweiz. Pöyry Management Consulting (Schweiz).

Poyry, 2012b. Impact of EMR on interconnection. Pöyry Management Consulting (UK) Ltd. Rai, A.M., Reedman, L., Graham, P., 2014. Price and income elasticities of residential electricity demand: the Australian evidence.

Ros, A.J., 2015. An Econometric Assessment of Electricity Demand in the United States Using Panel Data and the Impact of Retail Competition on Prices.

Royal Academy of Engineering, 2013. GB electricity capacity margin.

SFOE, 2014a. Schweizerische Statistik der erneuerbaren Energien. Ausgabe 2013. Swiss Federal Office of Energy.

SFOE, 2014b. Statistique suisse de l'électricité 2013. Swiss Federal Office of Energy.

SFOE, 2014c. Statistique des aménagements hydroélectriques de la Suisse 2014. Swiss Federal Office of Energy.

SFOE, 2013. Perspectives énergétiques 2050. Swiss Federal Office of Energy.

SFOE, 2012. Le potentiel hydroélectrique de la Suisse. Swiss Federal Office of Energy.

Sterman, J.D., 2000. Business Dynamics: Systems Thinking and Modeling for a Complex World with CD-ROM, HAR/CDR edition. ed. McGraw-Hill Education, Boston. Swiss Confederation Administration, 2013. Initiative populaire fédérale "Pour la sortie programmée de l’énergie nucléaire (Initiative «Sortir du nucléaire»)' [WWW Document]. URL http://www.admin.ch/ch/f/pore/vi/vis407t.html (accessed 1.16.15). 
Swissgrid, 2015. Swissgrid - Europe [WWW Document]. URL http://www.swissgrid.ch/swissgrid/en/home/europa.html (accessed 1.16.15).

Swissgrid, 2013. Energy Statistic Switzerland 2012. Swissgrid.

Teufel, F., Miller, M., Genoese, M., Fichtner, W., 2013. Review of System Dynamics models for electricity market simulations (Working Paper Series in Production and Energy No. 2). Karlsruhe Institute of Technology.

The Swiss Federal Council, 2015. Ordonnance sur l'énergie (OEne), 730.01.

The Swiss Federal Council, 2013. Loi sur l'énergie (LEne) (Projet).

The Swiss Federal Council, 2011. Fiche d'information: Perspectives énergétiques 2050 Analyse des variantes d'offre d'électricité du Conseil fédéral.

Ueckerdt, F., Hirth, L., Luderer, G., Edenhofer, O., 2013. System LCOE: What are the costs of variable renewables? Energy 63, 61-75. doi:10.1016/j.energy.2013.10.072

van Ackere, A., Ochoa, P., 2010. Managing a hydro-energy reservoir: A policy approach. Energy Policy, Energy Efficiency Policies and Strategies with regular papers. 38, 7299-7311. doi:10.1016/j.enpol.2010.08.005 


\section{TABLES}

Table 1. Main statistics of the Swiss electricity market in 2013 (SFOE, 2014b).

\begin{tabular}{|c|c|c|}
\hline & $\begin{array}{c}\text { Volume } \\
\text { (GWh) }\end{array}$ & Share \\
\hline Total production & 68,312 & $100 \%$ \\
\hline Run-of-river & 17,759 & $26 \%$ \\
\hline Hydro-storage & 21,813 & $32 \%$ \\
\hline Nuclear & 24,871 & $26 \%$ \\
\hline Others & 3,869 & $6 \%$ \\
\hline Net production & 66,180 & \\
\hline Pumping & 2,132 & \\
\hline Net exports & 2,396 & \\
\hline National consumption & 63,784 & \\
\hline
\end{tabular}


Table 2. Main simulation parameters.

\begin{tabular}{|c|c|c|c|c|c|c|}
\hline & $\begin{array}{l}\text { Initial } \\
\text { capacity } \\
(\mathrm{MW})^{\mathrm{a}}\end{array}$ & $\begin{array}{c}\text { Expansion } \\
\text { potential } \\
(\mathrm{MW})^{\mathrm{b}, \mathrm{c}}\end{array}$ & $\begin{array}{l}\text { Annual } \\
\text { fixed costs } \\
(\mathrm{CHF} / \\
\mathrm{MW})^{\mathrm{d}}\end{array}$ & $\begin{array}{c}\text { Marginal } \\
\text { cost } \\
(\mathrm{CHF} / \\
\text { MWh })^{d}\end{array}$ & $\begin{array}{l}\text { Lifetime } \\
\text { (years) }^{d, e}\end{array}$ & $\begin{array}{c}\text { Average } \\
\text { availability } \\
\text { factors }^{b}\end{array}$ \\
\hline $\begin{array}{l}\text { Hydro Storage } \\
\text { (HS) }\end{array}$ & 9,920 & 1,311 & 24,000 & $6-56^{*}$ & 80 & $28 \%$ \\
\hline $\begin{array}{l}\text { Run-of-River } \\
\text { (RR) }\end{array}$ & 3,853 & 254 & 53,000 & 11 & 80 & $65 \%$ \\
\hline Nuclear (NUC) & 3,278 & 0 & 89,760 & 10 & 50 & $89 \%$ \\
\hline CCGT (CCGT) & 89 & 3,167 & 42,000 & $45-65 * *$ & 30 & $92 \%$ \\
\hline $\begin{array}{l}\text { Photovoltaic } \\
\text { (PV) }\end{array}$ & 755 & 18,947 & 23,000 & 2 & 20 & $11 \%$ \\
\hline $\begin{array}{l}\text { Wind energy } \\
\text { (WI) }\end{array}$ & 60 & 2,222 & 38,400 & 1 & 20 & $18 \%$ \\
\hline $\begin{array}{l}\text { Other thermal } \\
\text { (TH) }\end{array}$ & 760 & 1,333 & 25,000 & $\begin{array}{r}4-21 \\
* * / * * *\end{array}$ & 20 & $51 \%$ \\
\hline Total & 18,715 & 27,234 & & & & \\
\hline \multicolumn{7}{|c|}{ a (SFOE, 2014a, 2014c, 2014b) } \\
\hline \multicolumn{7}{|l|}{ b (AES, 2012) } \\
\hline \multicolumn{7}{|l|}{ c (SFOE, 2012) } \\
\hline \multicolumn{7}{|l|}{ d (Poyry, 2012a) } \\
\hline \multicolumn{7}{|c|}{ e (Kannan and Turton, 2012) } \\
\hline *Opportunity cost, & ch depends o & n reservoir leve & and on the pri & of other $\mathrm{p}$ & ducers. & \\
\hline$* *$ We assume step- & increases & fuel and $\mathrm{CO}$ & ices over the & ulation $\mathrm{p}$ & d (Poyry, & ). \\
\hline
\end{tabular}


Table 3. Comparison among scenarios of demand.

\begin{tabular}{|l|r|r|r|}
\hline & \multicolumn{1}{|c|}{ BAU } & \multicolumn{1}{c|}{ DS } & \multicolumn{1}{c|}{ DD } \\
\hline Average Price (CHF/MWh) & 49.2 & 46.4 & 45.1 \\
\hline Average exports (TWh/year) & 31.7 & 33.2 & 33.9 \\
\hline Average imports (TWh/year) & 36.6 & 32.8 & 30.4 \\
\hline Average net imports (TWh/year) & 4.9 & -0.4 & -3.5 \\
\hline
\end{tabular}

Table A1. Model variables and sub-indexes.

\begin{tabular}{|c|c|}
\hline \multicolumn{2}{|r|}{ Sub-indexes } \\
\hline$t$ & Time $(0, \ldots 147)$ [quarters] \\
\hline$T, n$ & $\begin{array}{l}\text { Technology (Hydro-storage }[\mathrm{HS}] \text {, run-of-river }[\mathrm{RR}] \text {, nuclear }[\mathrm{NUC}] \text {, } \\
\text { Combined cycle gas turbine }[\mathrm{CCGT}] \text {, photovoltaic }[\mathrm{PV}] \text {, wind energy }[\mathrm{WI}] \text {, } \\
\text { other thermal }[\mathrm{TH}] \text { ) }\end{array}$ \\
\hline$j$ & $\begin{array}{l}\text { Producers: these include the different technologies (HS, RR, NUC, CCGT, } \\
\text { PV, WI, TH) and imports (long term import contracts [LTI] and balancing } \\
\text { imports [BI]) }\end{array}$ \\
\hline$h$ & Hour of the day $(1, \ldots 24)$ \\
\hline$s$ & Season (Winter [s=0], Spring [s=1], Summer [s=2], Autumn [s=3]) \\
\hline$c$ & Countries to where electricity is exported (France, Germany and Italy) \\
\hline$e$ & $\begin{array}{l}\text { Possible capacity investments sizes }(1, \ldots 10) \text {, with } 1 \text { being the smallest and } \\
10 \text { the largest }\end{array}$ \\
\hline \multicolumn{2}{|r|}{ Parameters } \\
\hline$L_{T}$ & Lifespan of technology $T$ (quarters) \\
\hline$E P_{c, h}$ & Maximum price paid by each country $c$ to where export go at hour $h$ \\
\hline
\end{tabular}




\begin{tabular}{|c|c|}
\hline & (CHF/MWh) \\
\hline \multicolumn{2}{|r|}{ Variables } \\
\hline$K_{T, t}$ & Installed capacity of technology $T$ (MW) \\
\hline$E K_{T, t}$ & New capacity of technology $T$ coming online (MW/quarter) \\
\hline$O K_{T, t}$ & Obsolescence of capacity of technology $T$ (MW/quarter) \\
\hline$C K_{T, t}$ & Construction start of capacity of technology $T$ (MW/quarter) \\
\hline$U K_{T, t}$ & Capacity under construction of technology $T(\mathrm{MW})$ \\
\hline ConsD $_{T}$ & Construction delay of technology $T$ (quarters) \\
\hline $\operatorname{OldK}_{T, t}$ & $\begin{array}{l}\text { Capacity of technology } T \text { that was installed before } 2013 \text { and remains } \\
\text { available at time } \mathrm{t}(\mathrm{MW})\end{array}$ \\
\hline$A_{T, h, t}$ & Availability factor of technology $T$ at hour h (\%) \\
\hline$S_{j, h, t}$ & Available supply from producer $j$ at hour $h(\mathrm{MWh})$ \\
\hline$M C_{j, h, t}$ & $\begin{array}{l}\text { Marginal costs of producer } j \text { at hour } h \text {, i.e., price at which each producer } \\
\text { bids in the day-ahead auction ( } \mathrm{CHF} / \mathrm{MWh})\end{array}$ \\
\hline$V C_{j, t}$ & Variable production costs of producers $j(\mathrm{CHF} / \mathrm{MWh})$ \\
\hline$D_{h, t}$ & Hourly national demand (MWh) \\
\hline$S D_{j, h, t}$ & $\begin{array}{l}\text { Supply dispatched from producer } j \text { during hour } h \text { in the Swiss market } \\
\text { (MWh) }\end{array}$ \\
\hline$S R_{j, h, t}$ & $\begin{array}{l}\text { Remaining available supply from producer } j \text { during hour } h \text { after national } \\
\text { dispatch, i.e., supply available for exports (MWh) }\end{array}$ \\
\hline$D E_{c, h, t}$ & Demand for imports from Switzerland by country $c$ during hour $h(\mathrm{MWh})$ \\
\hline$E S_{j, c, h, t}$ & Supply from producer $j$ exported to country $c$ during hour $h(\mathrm{MWh})$ \\
\hline$Q_{j, t}$ & Total supply from producer $j$ in a quarter $t(\mathrm{MWh})$ \\
\hline$R L_{t}$ & Reservoir level (\%) \\
\hline
\end{tabular}




\begin{tabular}{|c|c|}
\hline$F R L_{t}$ & Forecasted reservoir level before production (\%) \\
\hline$W_{t}$ & Stock of water in the reservoir (MWh) \\
\hline$I_{t}$ & Water inflow to reservoirs (MWh/quarter) \\
\hline$R_{t}$ & Reservoir capacity (MWh) \\
\hline Spill $_{t}$ & Water spillages (MWh) \\
\hline$F K_{T, t}$ & Future capacity of technology $T$ (in $\mathrm{t}+20[5$ years $]$ ) \\
\hline$F K E_{n, e, t}^{T}$ & $\begin{array}{l}\text { Forecast of future installed capacity (in } t+20 \text { [5 years]) of technologies } n \\
\text { made by technology } T \text {, assuming a capacity investment size } e(\mathrm{MW})\end{array}$ \\
\hline$O K_{T, t}^{*}$ & Obsolete capacity of technology $T$ over the next 5 years (MW) \\
\hline$P_{e, t}^{T}$ & $\begin{array}{l}\text { Expected price to be received by technology } T \text { assuming a capacity } \\
\text { investment of size } e(\mathrm{CHF} / \mathrm{MWh})\end{array}$ \\
\hline$E_{n, e, t}$ & $\begin{array}{l}\text { Capacity expansion of technology } n \text { assumed, assuming a capacity } \\
\text { investment of size } e(\mathrm{MW})\end{array}$ \\
\hline$X_{e, t}^{T}$ & $\begin{array}{l}\text { Expected profitability of technology } T \text { assuming a capacity investment of } \\
\text { size } e(\%)\end{array}$ \\
\hline$L C O E_{e, t}^{T}$ & $\begin{array}{l}\text { Levelised cost of electricity expected by a technology } T \text { assuming a capacity } \\
\text { investment of size } e(\mathrm{CHF} / \mathrm{MWh})\end{array}$ \\
\hline$K C_{T, t}$ & Annualised capital costs of technology $T(\mathrm{CHF} / \mathrm{MW})$ \\
\hline$F C_{T, t}$ & Fixed annual costs of technology $T(\mathrm{CHF} / \mathrm{MW})$ \\
\hline$E L F_{e, t}^{T}$ & $\begin{array}{l}\text { Expected load factor of technology } T \text { assuming a capacity investment of size } \\
e(\mathrm{MWh} / \mathrm{MW})\end{array}$ \\
\hline$W_{e, t}^{T}$ & $\begin{array}{l}\text { Binary variable for expected profitability of technology } \mathrm{T} \text { assuming a } \\
\text { capacity investment of size } e\end{array}$ \\
\hline
\end{tabular}


Table B1. De-rated factors for the technologies considered (AES, 2012; Poyry, 2012b).

\begin{tabular}{|l|r|}
\hline \multicolumn{1}{|c|}{ Technologies } & De-rating factors \\
\hline Hydro Storage & $84 \%$ \\
\hline Run-of-the-River & $34 \%$ \\
\hline Nuclear & $89 \%$ \\
\hline CCGT & $92 \%$ \\
\hline Photovoltaic & $0 \%$ \\
\hline Wind energy & $24 \%$ \\
\hline Other thermal & $51 \%$ \\
\hline
\end{tabular}

\section{FIGURES}

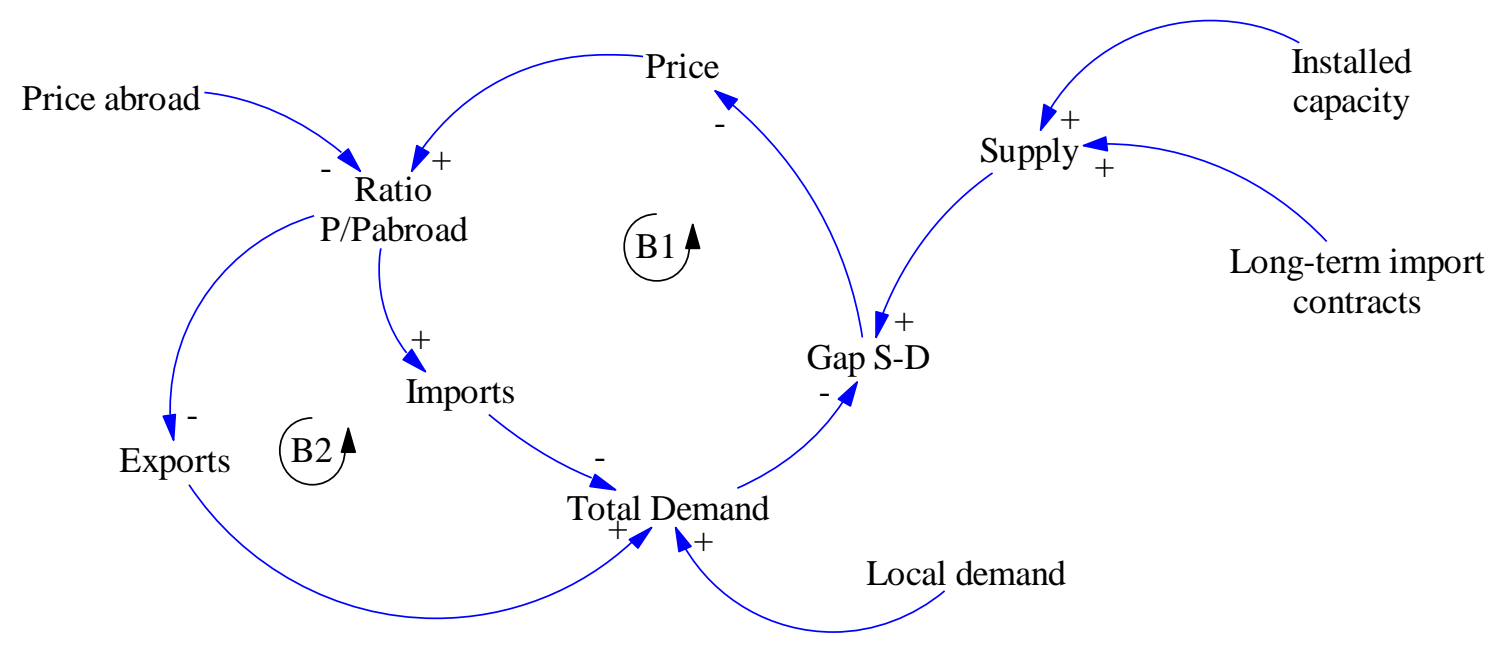

Figure 1. Electricity exchange and market clearance. 


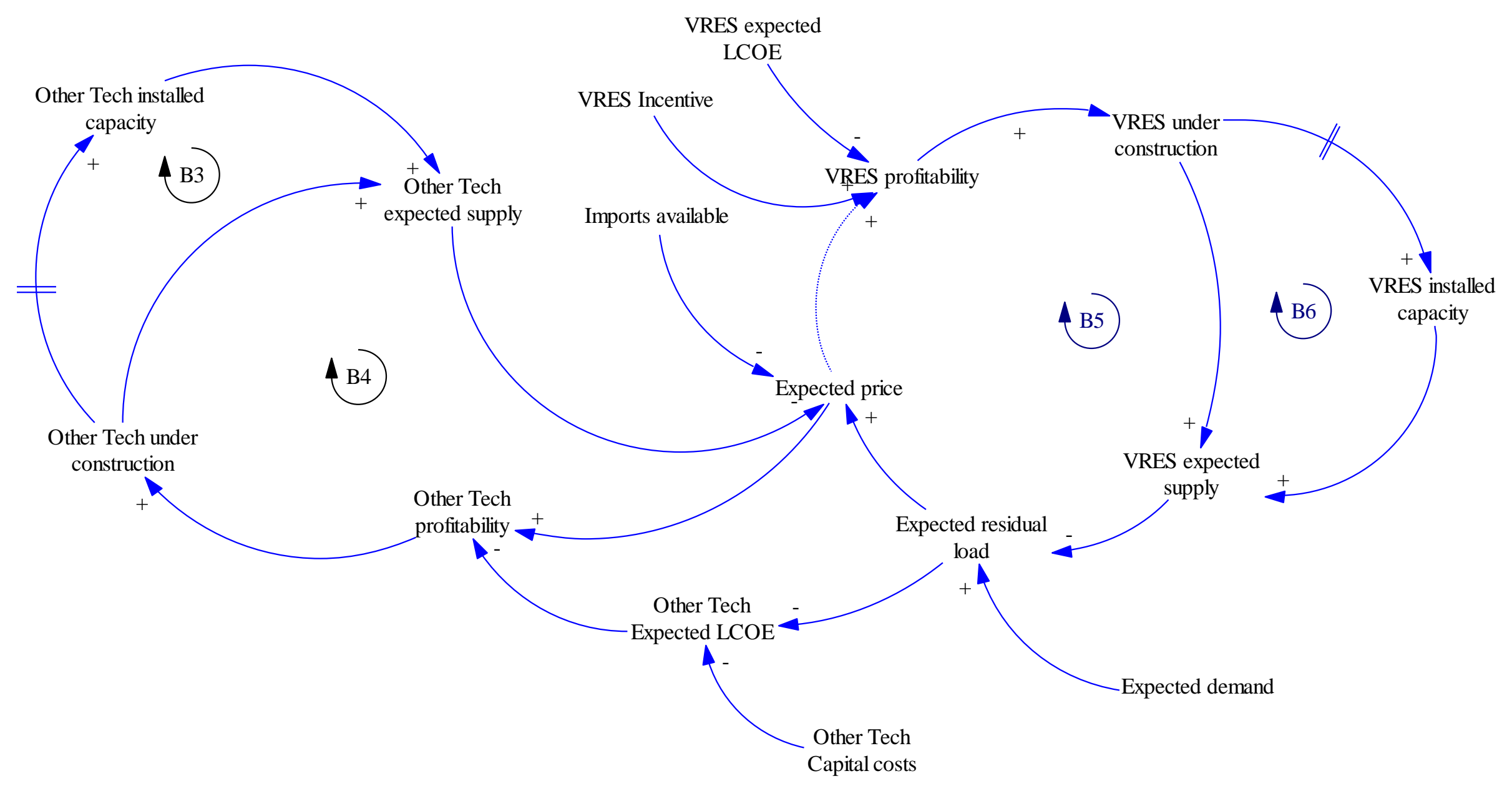

Figure 2. VRES effect on the investment decision process. 


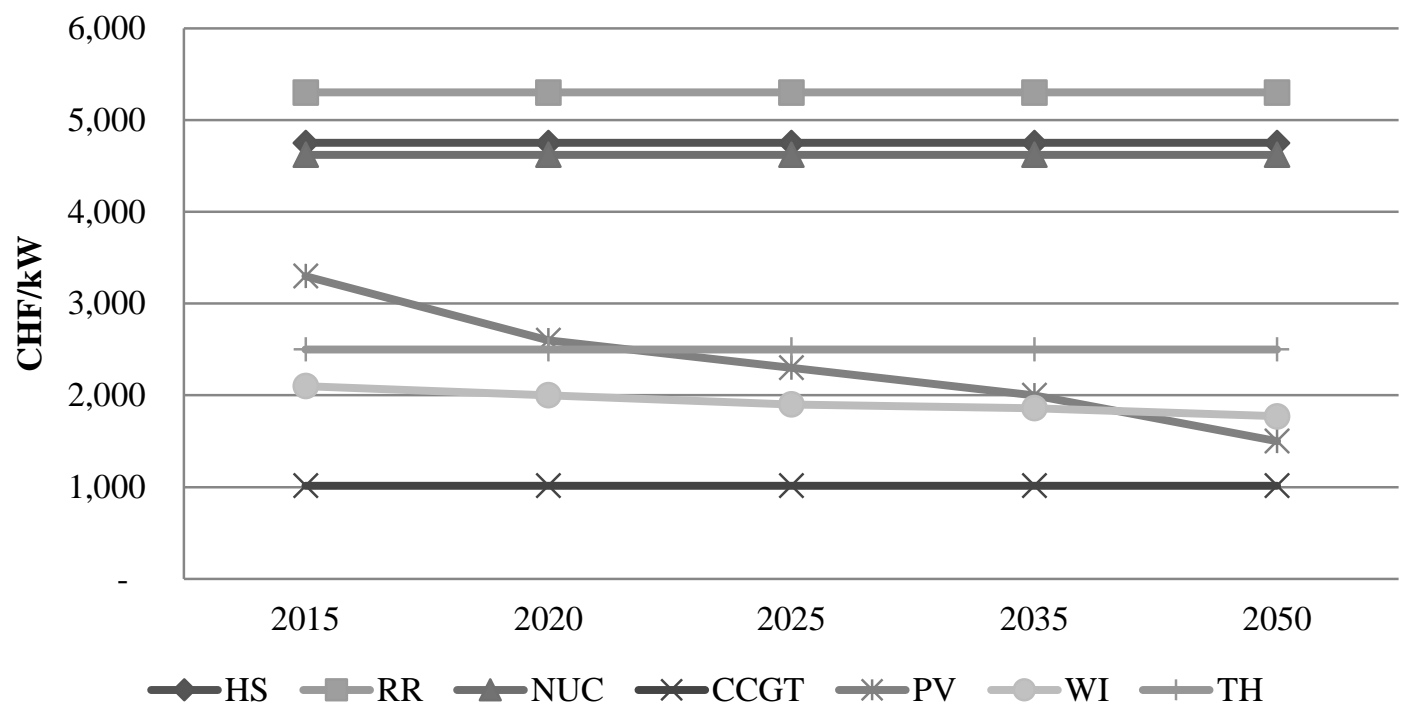

Figure 3. Capital costs of technologies considered in the model. Data from Poyry (2012a).

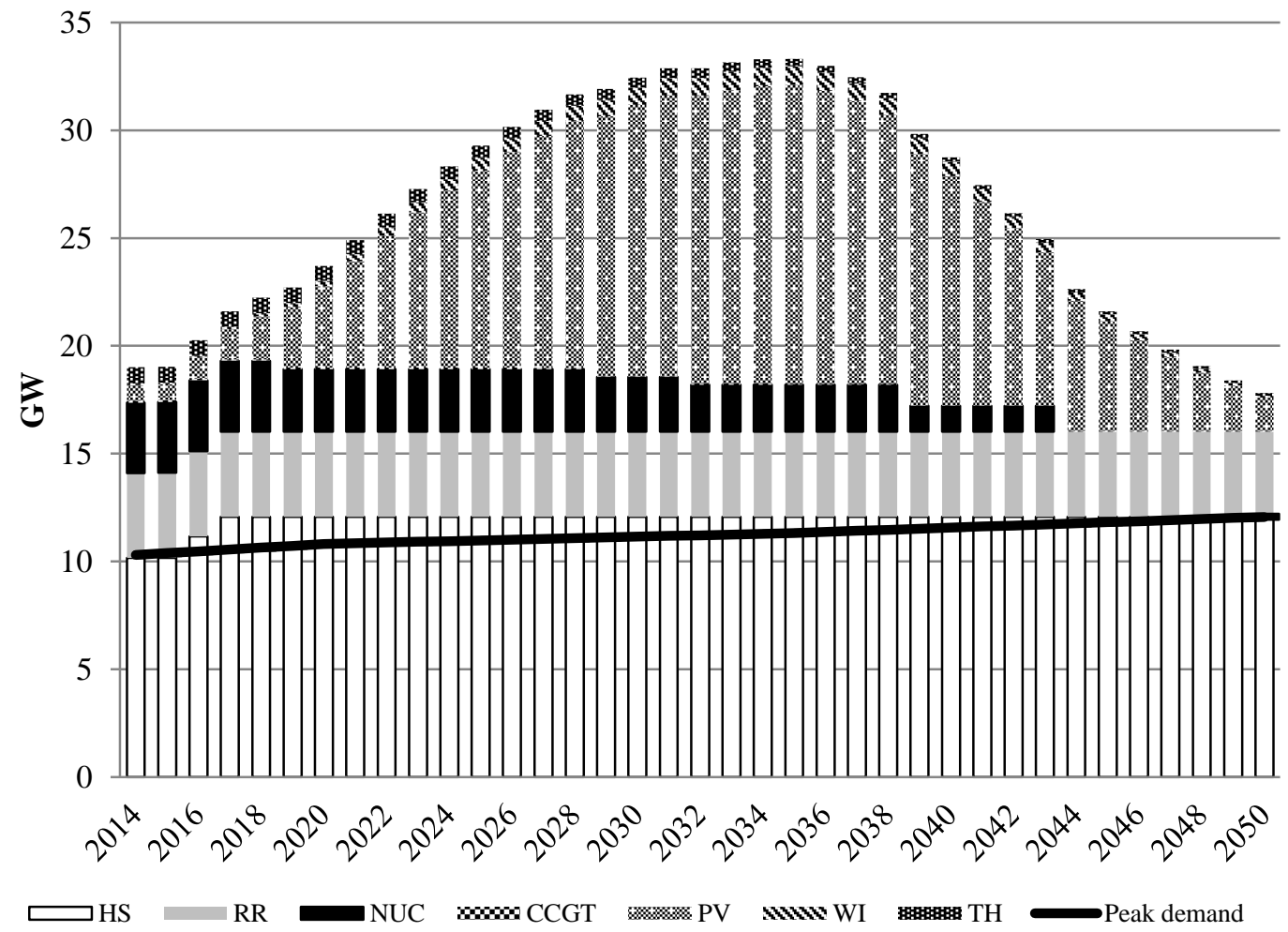

Figure 4. Simulation of installed capacity and peak demand from 2014 to 2050. 


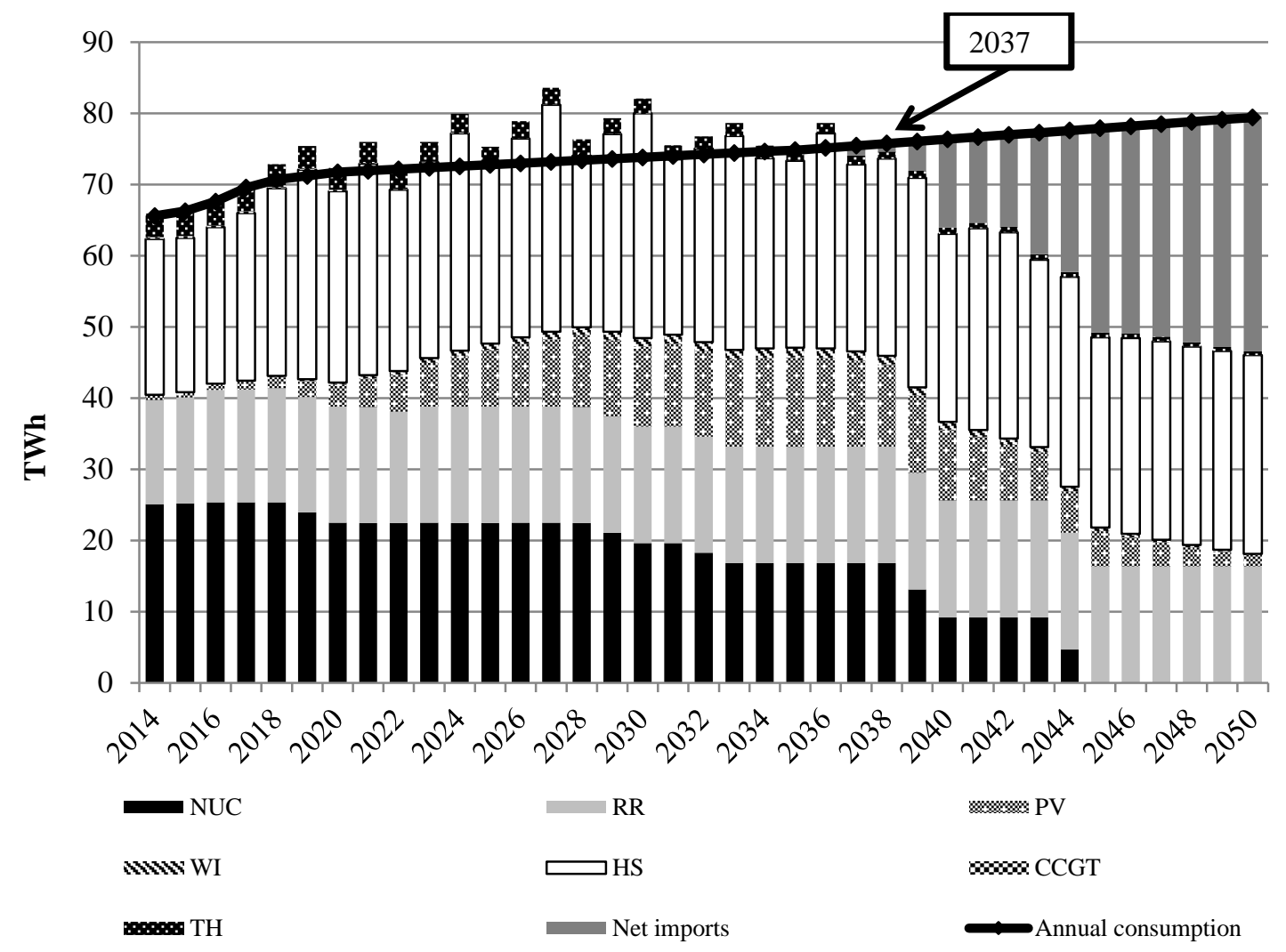

Figure 5. Simulation of energy mix of Swiss net production from 2014 to 2050.

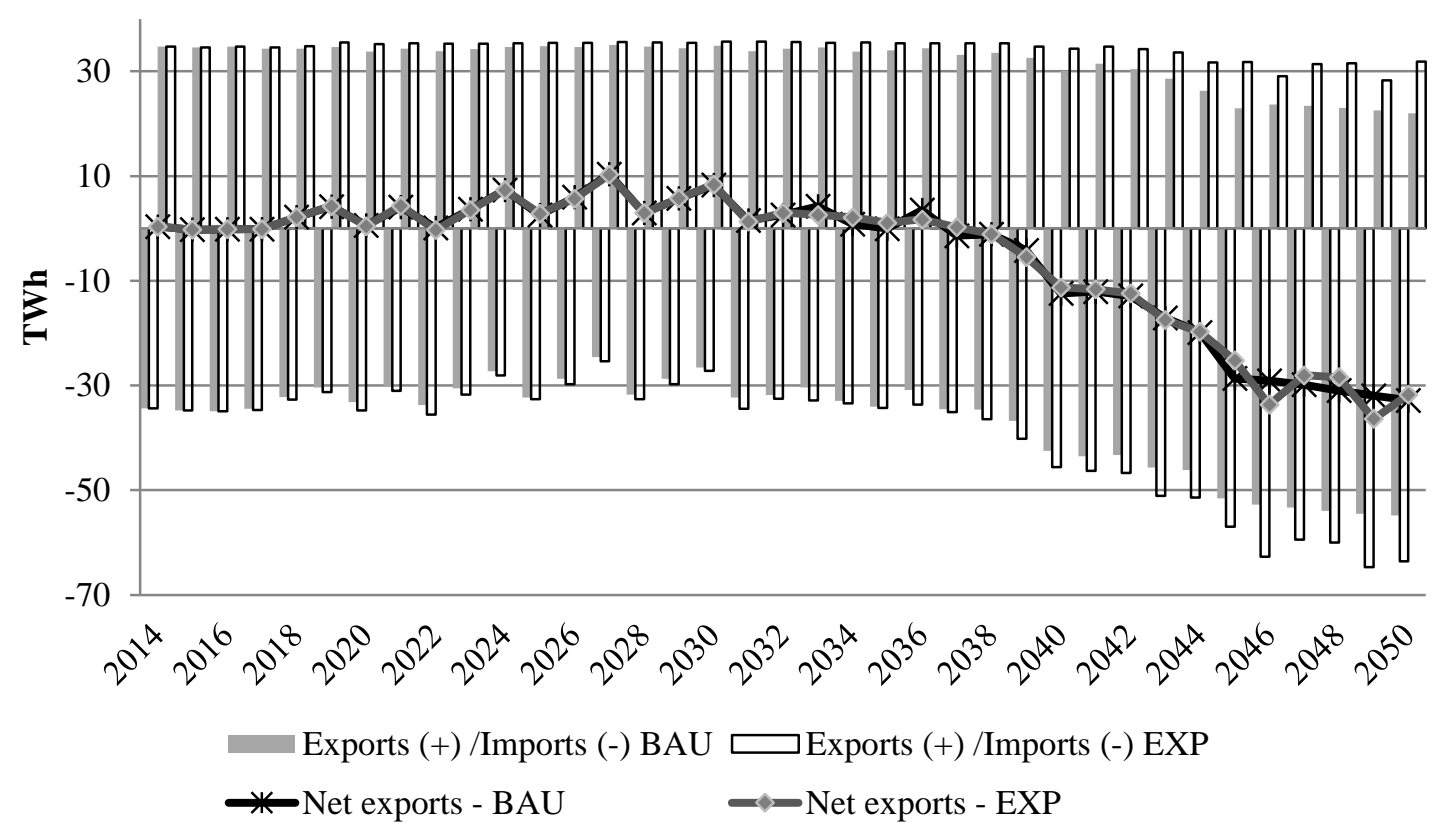

Figure 6. Exchange of electricity under $B A U$ and $E X P$ scenarios. Exports are expressed in positive values, while imports are expressed in negative values. 


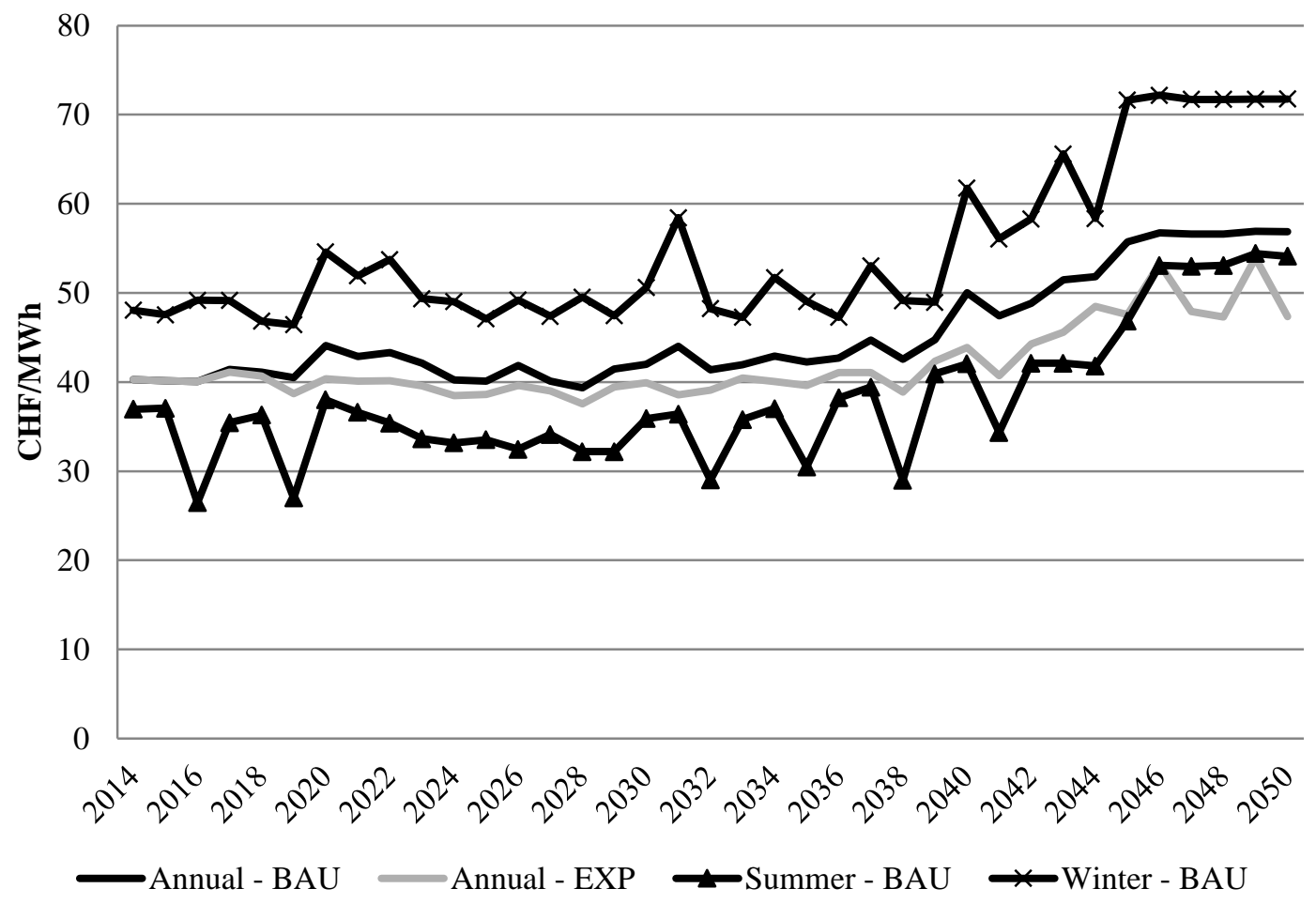

Figure 7. Seasonal and annual average wholesale prices in $B A U$ and $E X P$.

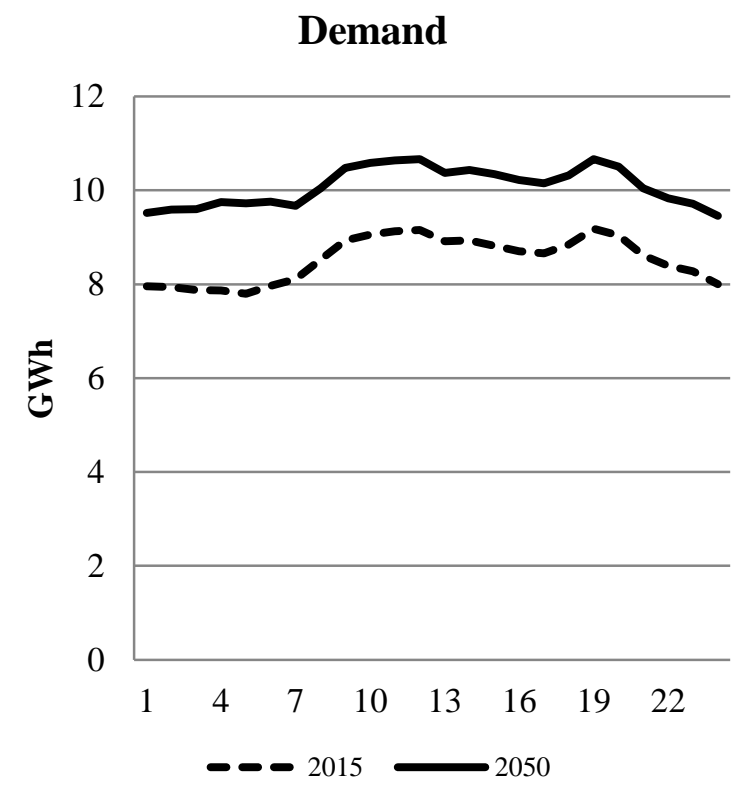

Price

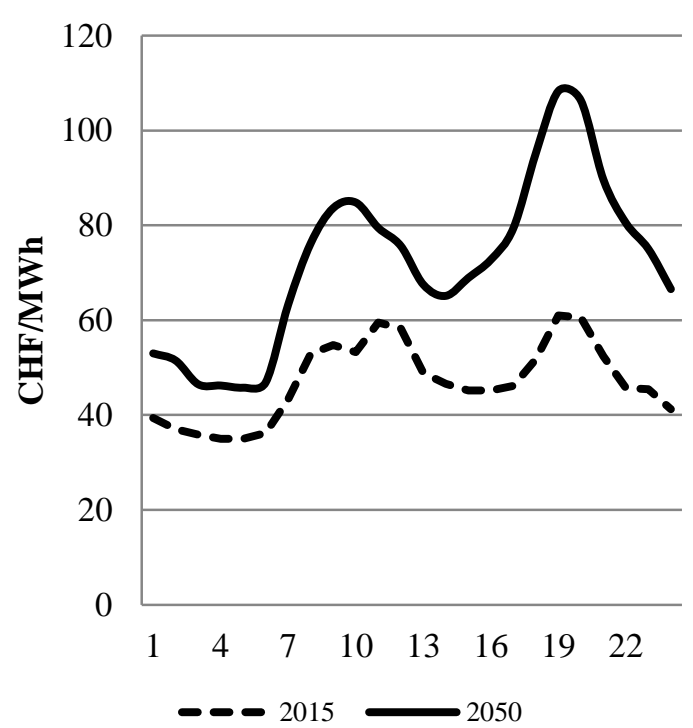

Figure 8. Comparison between hourly demand and prices in winter in 2015 and 2050. 


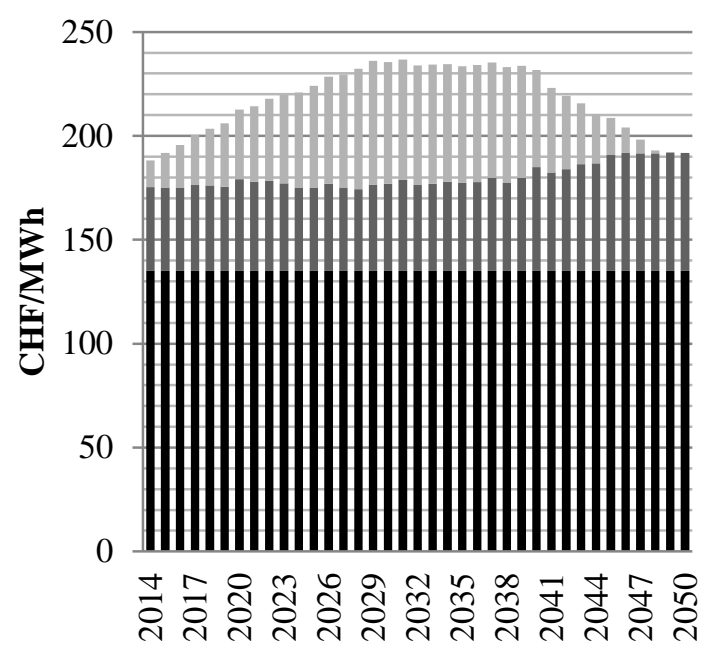

- Other levies $\square$ Wholesale price $\quad$ RPC

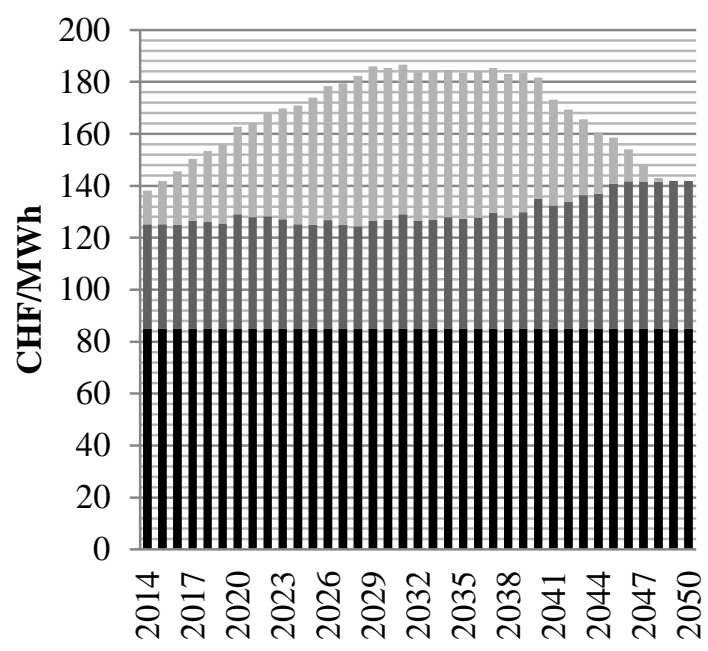

- Other levies $\quad$ Wholesale price $\quad \mathrm{RPC}$

Figure 9. Composition of household (left) and industry (right) tariffs.

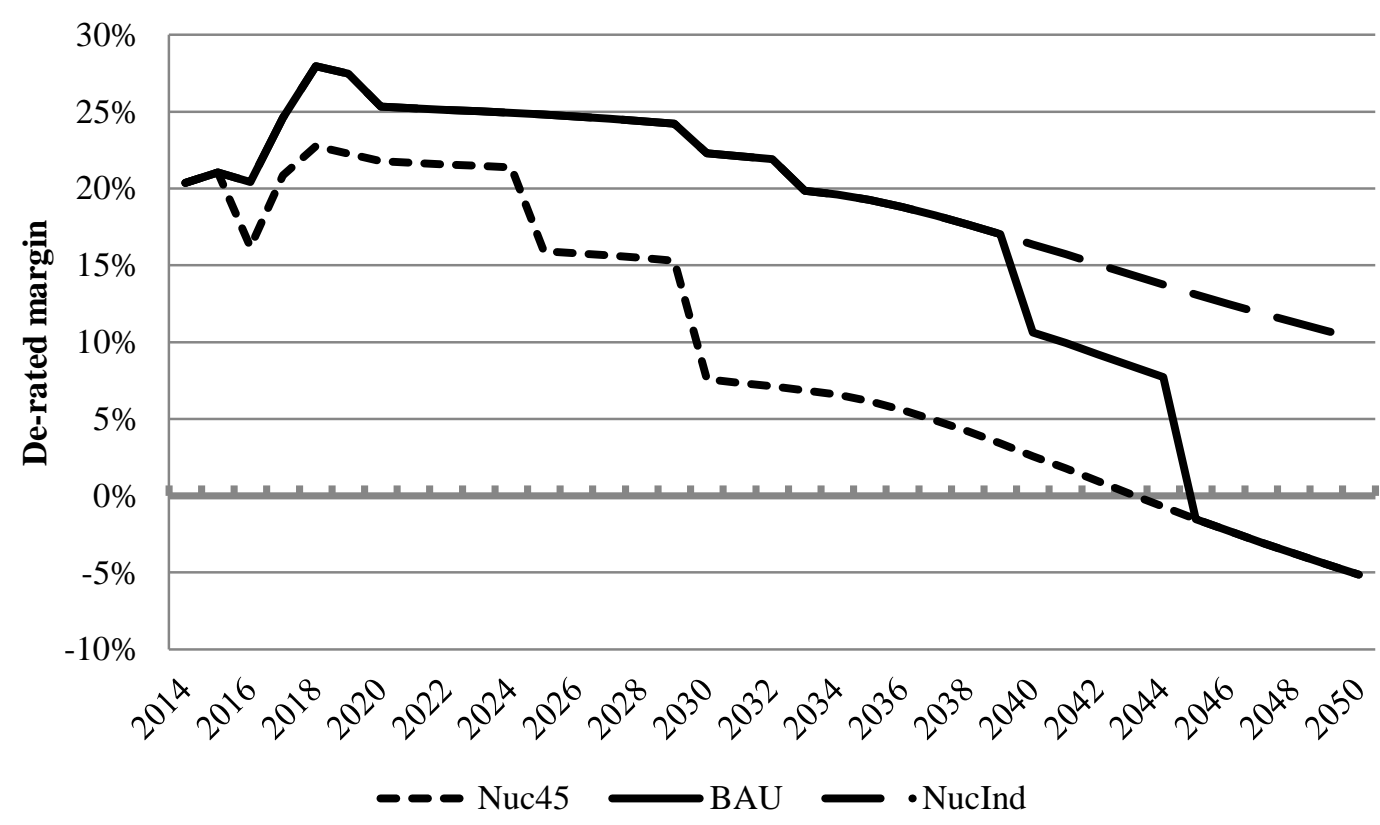

Figure 10. Evolution of the de-rated margin for the three scenarios. 


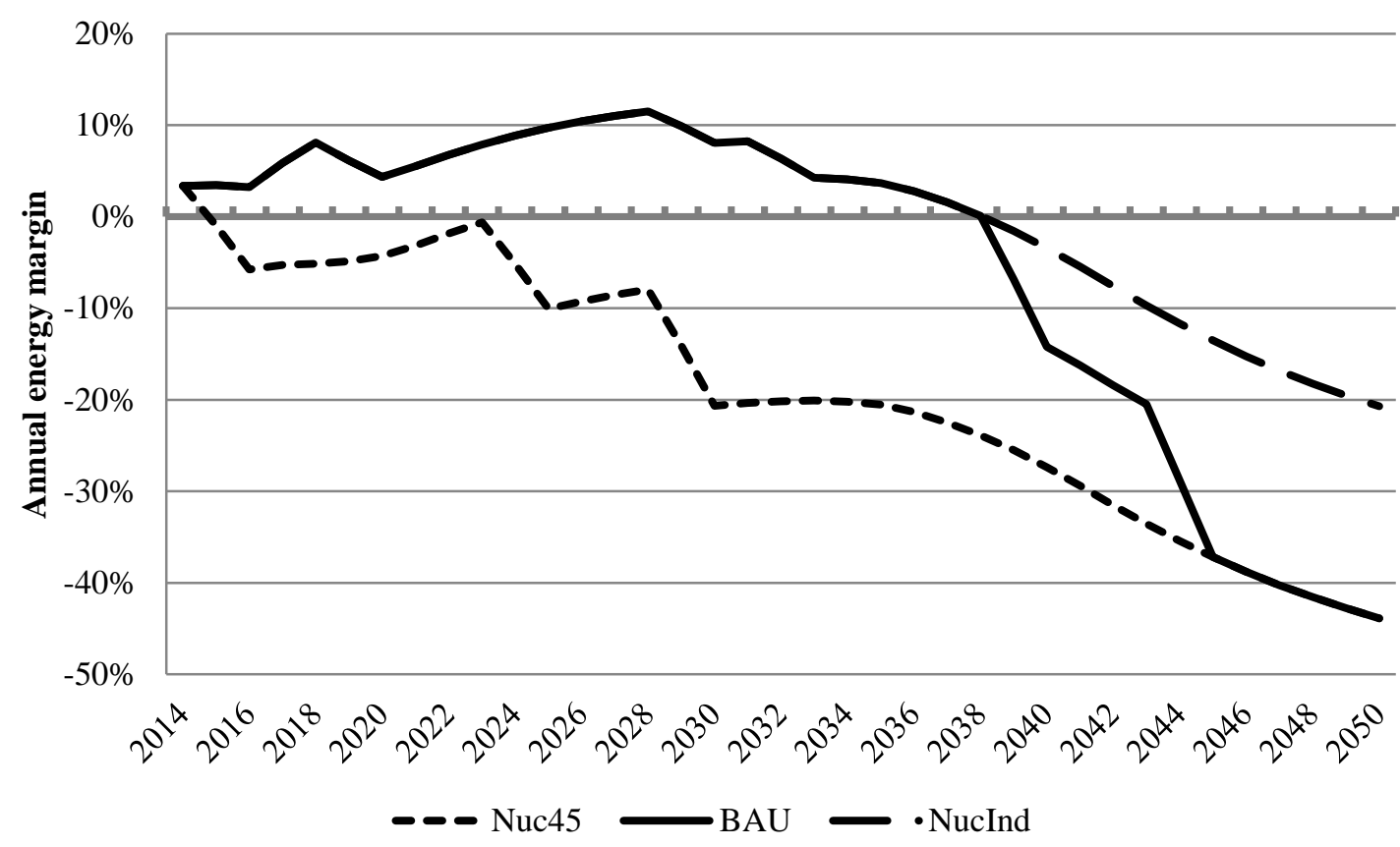

Figure 11. Evolution of the annual energy margin for the three scenarios.

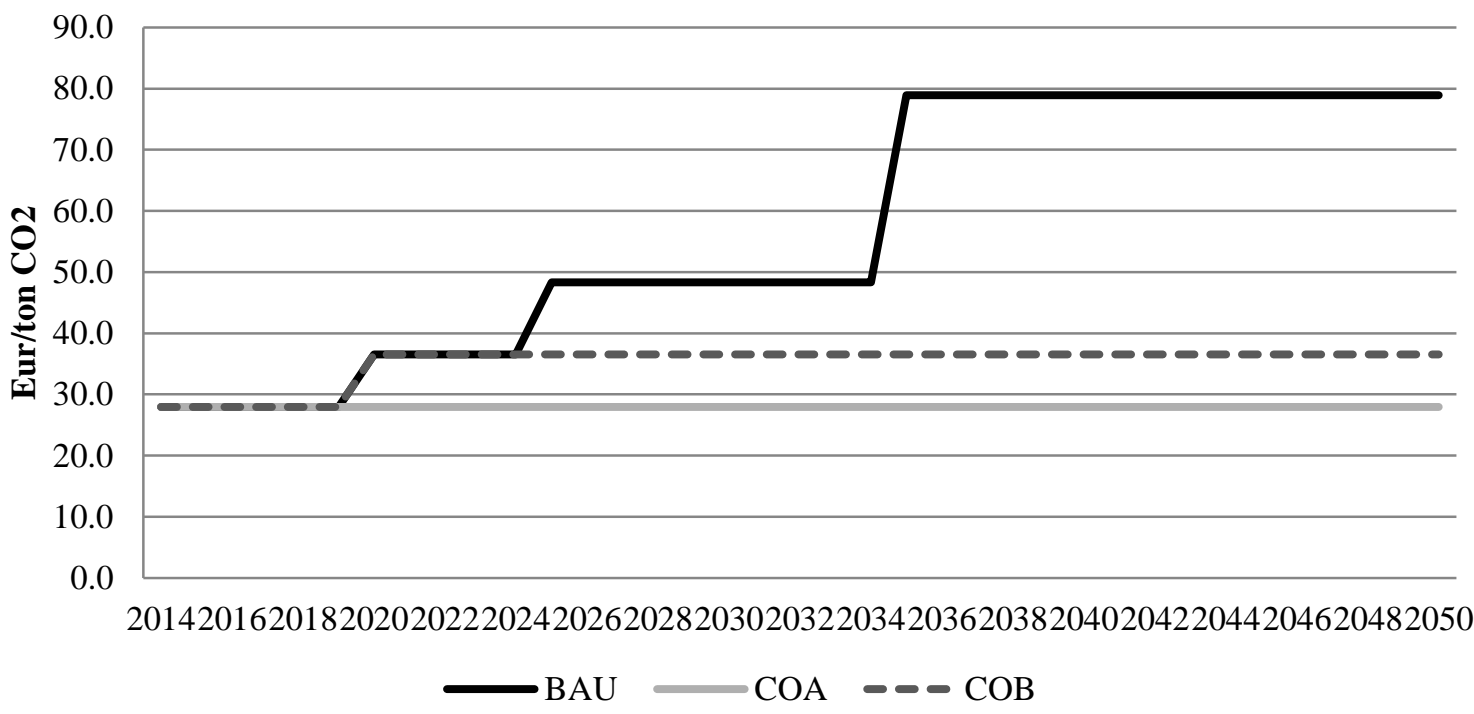

Figure 12. Scenarios of $\mathrm{CO}_{2}$ prices. 


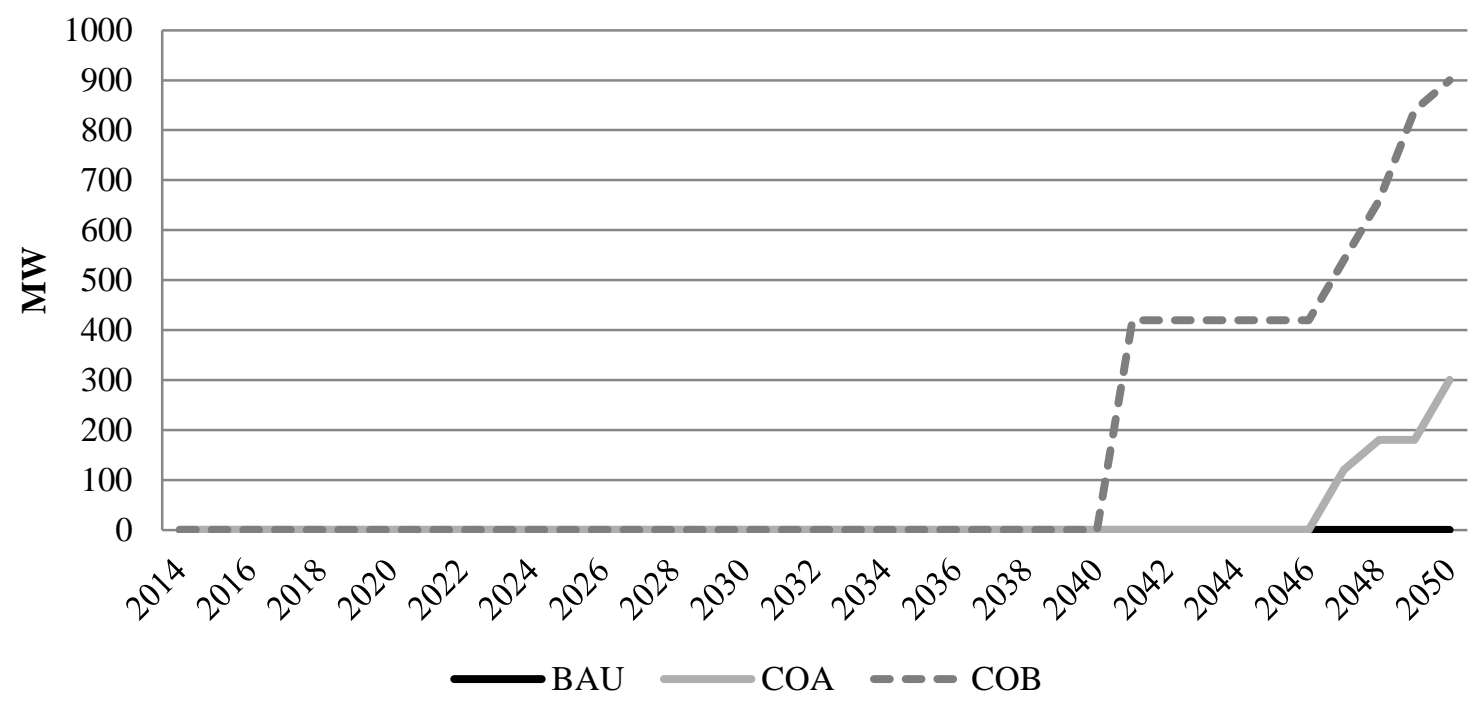

Figure 13. Installed capacity of CCGT under different $\mathrm{CO}_{2}$ scenarios.

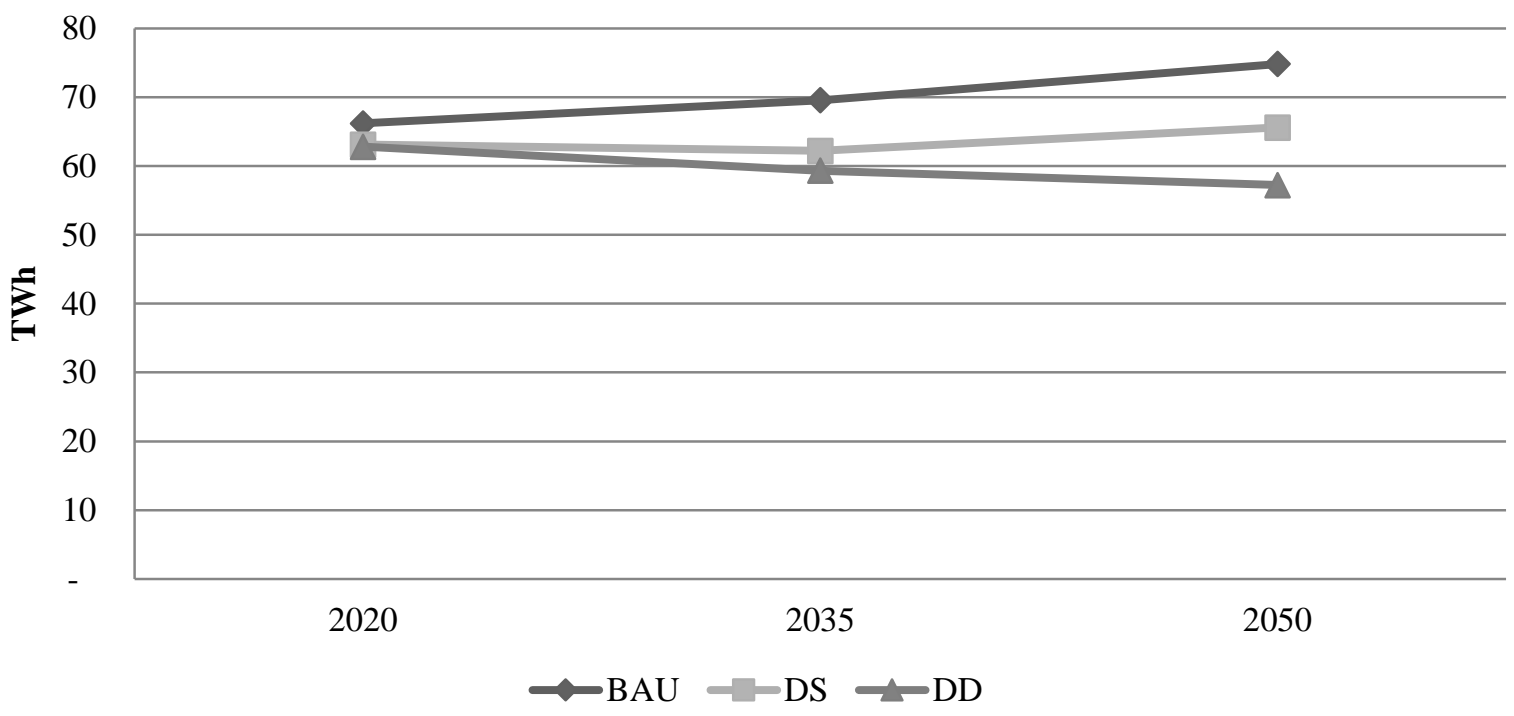

Figure 14. Annual demand for scenarios $B A U, D S$ and $D D$. Forecast adapted from SFOE (2013) using SFOE (2014b) data. 


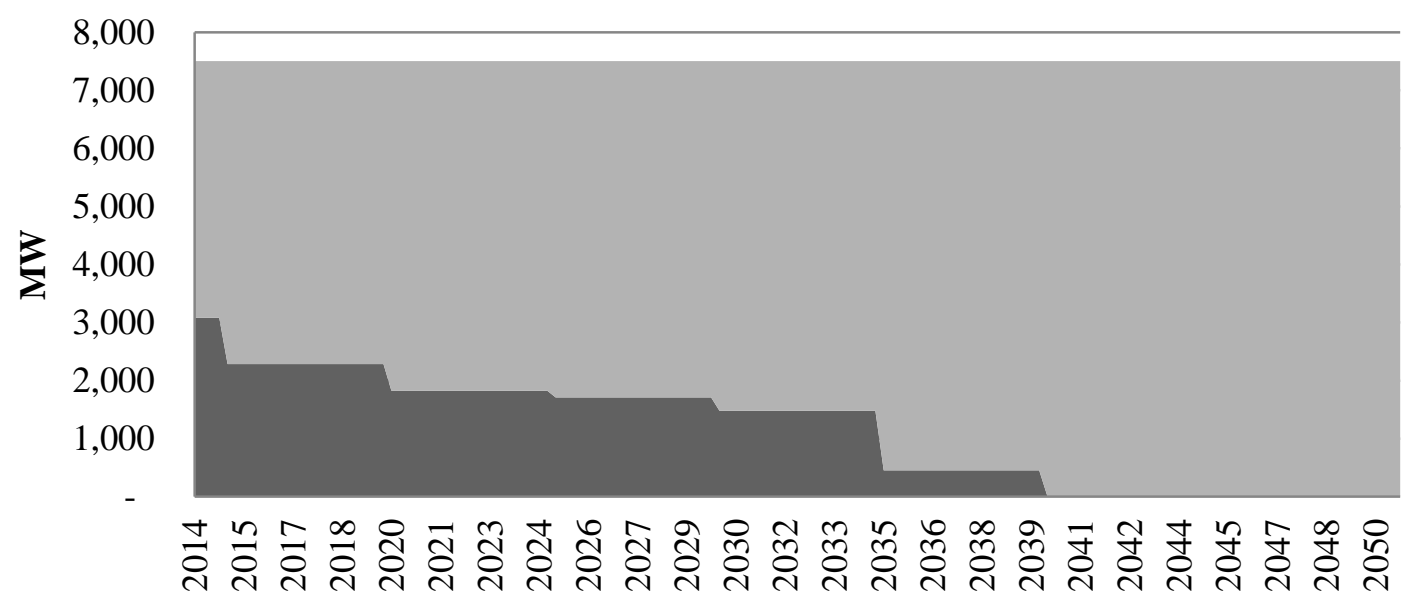

- Long-term contracts $\quad$ Short-term

Figure A1. Imports availability by type in $B A U$. Data for long-term import availability $\left(A_{L T I, h, t}\right)$ from AES

(2012).

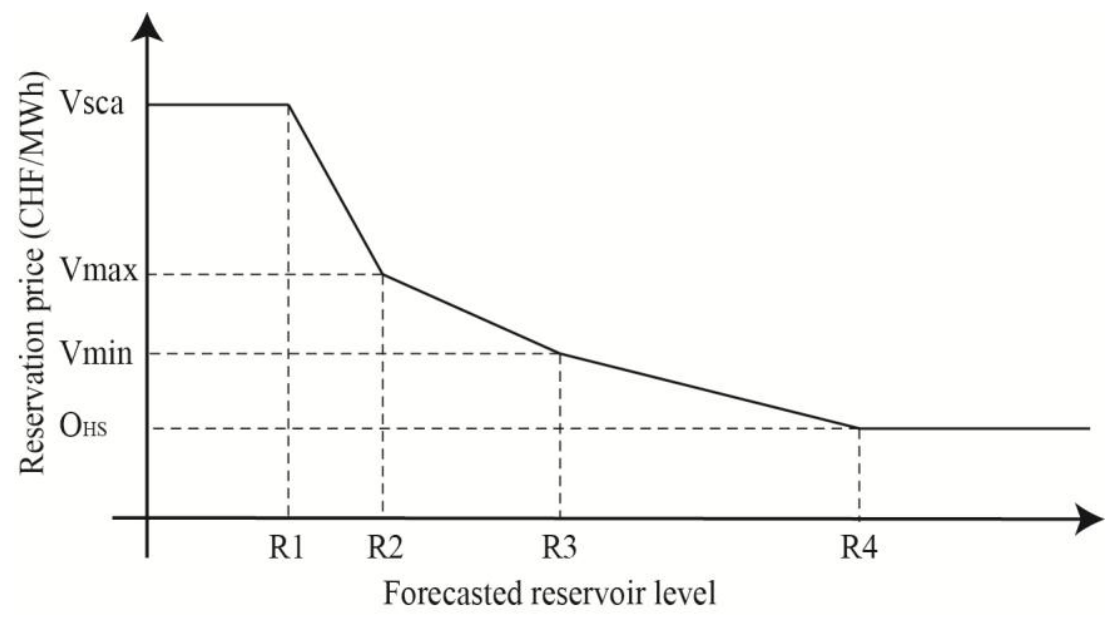

Figure A2. Modelling of hydro-storage reservation prices. 


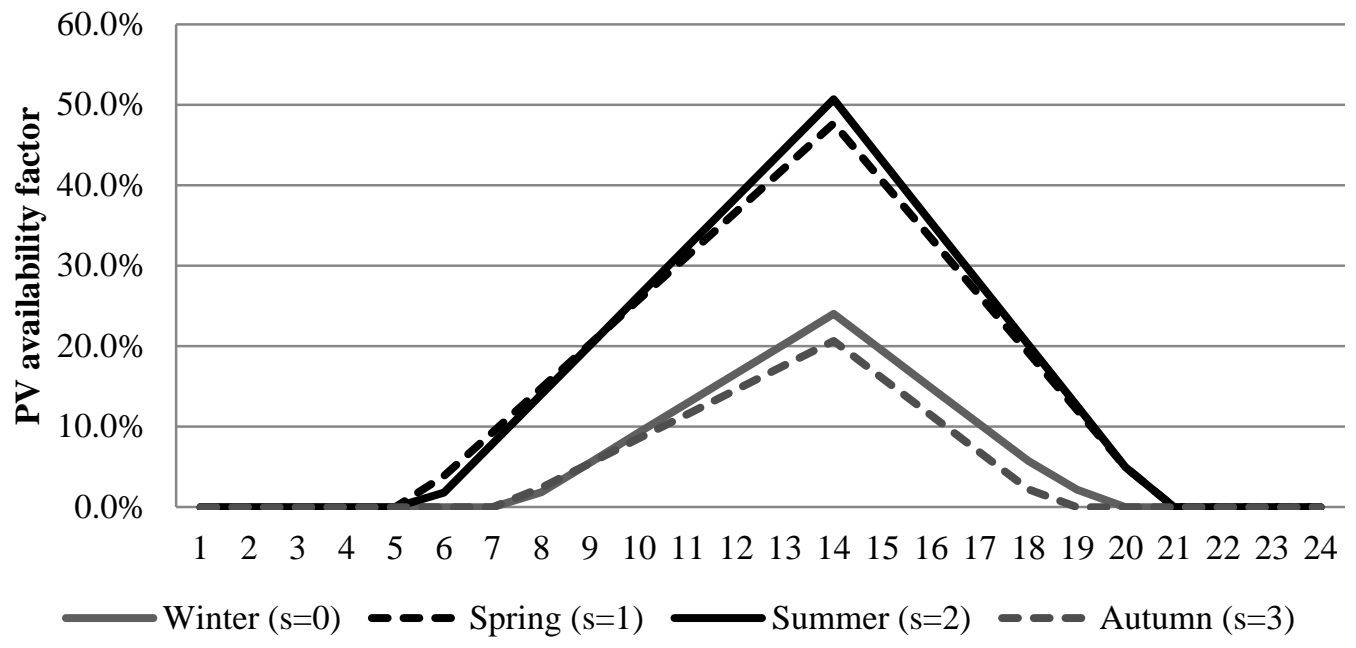

Figure A3. Seasonal availability factor of PV. 